\title{
Review Article \\ Involvement of Noncoding RNAs in the Differentiation of Osteoclasts
}

\author{
Yi Zhao, ${ }^{1}$ Lingfei Jia, ${ }^{2,3}$ Yunfei Zheng $\mathbb{D}^{1},{ }^{1}$ and Weiran Li $\mathbb{D}^{1}$ \\ ${ }^{1}$ Department of Orthodontics, Peking University School and Hospital of Stomatology, Beijing 100081, China \\ ${ }^{2}$ Department of Oral and Maxillofacial Surgery, Peking University School and Hospital of Stomatology, Beijing 100081, China \\ ${ }^{3}$ Central Laboratory, Peking University School and Hospital of Stomatology, Beijing 100081, China
}

Correspondence should be addressed to Yunfei Zheng; yunfei_zheng@bjmu.edu.cn and Weiran Li; weiranli@bjmu.edu.cn

Received 21 February 2020; Revised 11 August 2020; Accepted 14 August 2020; Published 25 August 2020

Academic Editor: Mahmood S. Choudhery

Copyright (c) 2020 Yi Zhao et al. This is an open access article distributed under the Creative Commons Attribution License, which permits unrestricted use, distribution, and reproduction in any medium, provided the original work is properly cited.

As the most important bone-resorbing cells, osteoclasts play fundamental roles in bone remodeling and skeletal health. Much effort has been focused on identifying the regulators of osteoclast metabolism. Noncoding RNAs (ncRNAs) reportedly regulate osteoclast formation, differentiation, survival, and bone-resorbing activity to participate in bone physiology and pathology. The present review intends to provide a general framework for how ncRNAs and their targets regulate osteoclast differentiation and the important events of osteoclastogenesis they are involved in, including osteoclast precursor generation, early differentiation, mononuclear osteoclast fusion, and multinucleated osteoclast function and survival. This framework is beneficial for understanding bone biology and for identifying the potential biomarkers or therapeutic targets of bone diseases. The review also summarizes the results of in vivo experiments and classic experiment methods for osteoclast-related researches.

\section{Introduction}

1.1. A Brief Introduction to Osteoclasts. Multinucleated osteoclasts are closely related to orthodontic tooth movement, as they can resorb mineralized bone and, together with osteoblasts, initiate the bone remodeling cycle [1]. Osteoclasts are also essential for continuous tooth movement as they remove adjacent bone and the necrotic tissue generated by periodontal ligament hyalinization [2, 3]. Moreover, bone is remodeled throughout life, which consists of osteoclasts resorbing old bone and osteoblasts synthesizing new bone. When the balance between these two processes is broken, many skeletal disorders occur [4, 5]. Enhanced osteoclast formation and activity contribute to bone loss of osteoporosis, rheumatoid arthritis, and osteolysis of metastatic tumors [6-8].

Osteoclasts are derived from macrophages and monocytes of hematopoietic lineage [5]. Within the bone marrow, stimulation of hematopoietic stem cells (HSCs) by stem cell factor (SCF), interleukin- (IL-) 3, and IL-6 yields common myeloid progenitors (CMPs). Then, stimulated with granulocyte/macrophage colony-stimulating factor (GM-CSF), CMPs differ- entiate into granulocyte/macrophage progenitors (GMPs). After being stimulated with macrophage colony-stimulating factor (M-CSF), GMPs further differentiate into cells of monocyte/macrophage lineage, which are considered osteoclast precursors (OCPs). OCPs express receptor activator of nuclear factor $\kappa \mathrm{B}$ (RANK) and colony-stimulating factor 1 receptor (CSF1R) [9]. Upon receptor activator of nuclear factor $\kappa \mathrm{B}$ ligand (RANKL) and M-CSF binding to RANK and CSF1R, respectively, OCPs then further differentiate into TRAP-positive mononuclear osteoclasts, which subsequently fuse to become multinucleated osteoclasts [10]. The sequential expression of $\mathrm{c}$-Fos, nuclear factor $\kappa \mathrm{B}(\mathrm{NF}-\kappa \mathrm{B})$, and nuclear factor of activated $\mathrm{T}$ cell cytoplasmic 1 (NFATc1), tartrateresistant acid phosphatase (TRAP), cathepsin K (CTSK), integrin $\beta 3$ (ITGB3), and calcitonin receptor (CALCR) are induced by RANKL and M-CSF [5]. They play important roles during these processes and lead to the formation of mature and activated osteoclasts, which marks the completion of osteoclastogenesis [11] (Figure 1).

1.2. A Brief Introduction to Noncoding RNAs. Noncoding RNAs (ncRNAs) are defined as RNAs that do not encode 


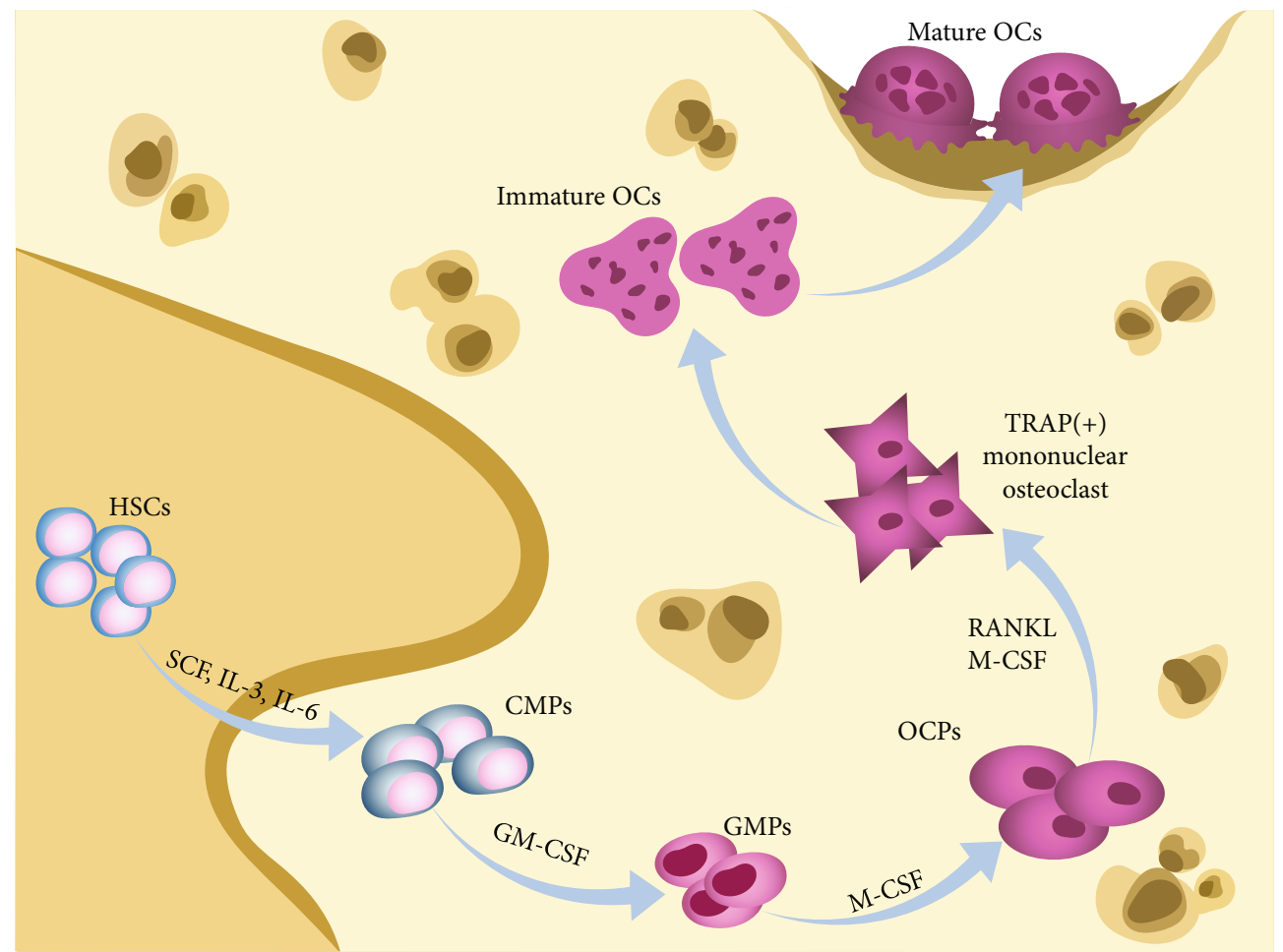

FIGURE 1: Osteoclastogenesis. Within the bone marrow, SCF, IL-3, and IL-6 stimulate HSCs to differentiate into CMPs. GM-CSF stimulates CMPs to differentiate into GMPs. M-CSF stimulates GMPs to differentiate into OCPs. OCPs express RANK and CSF1R. Upon RANKL and M-CSF binding to RANK and CSF1R, respectively, OCPs gradually differentiate to TRAP-positive mononuclear osteoclasts which then fuse to become multinucleated osteoclasts. Immature osteoclasts then undergo morphological changes and become mature and activated osteoclasts.

proteins [12] and include "housekeeping" rRNAs, tRNAs, small nuclear RNAs, and small nucleolar RNAs (snoRNAs) [13]. But ncRNAs are far more than these. Studies have shown that there are only approximately 20,000 proteincoding genes in the human genome, while at least $90 \%$ of the genome is actively transcribed which implies that about $80 \%$ of the genome is functional noncoding genes [14]. Although the transcripts of some such genes are suspected to be transcriptional noise, ncRNAs are important biological determinants and are recognized as a breakthrough for disease treatment in mechanism research, drug development, and new biomaterial invention $[13,15]$. In physiology and development of life, they control gene expression in multiple levels, including chromatin architecture/epigenetic memory, transcription, RNA splicing, editing, translation, and turnover [12]. ncRNAs are subdivided into two major classes according to their size: small ncRNAs $(<200 \mathrm{nt})$ and long ncRNAs (lncRNAs, $>200 \mathrm{nt}$ ) [14]. Small ncRNAs consist of microRNAs (miRNAs) which regulate posttranslational gene silencing, piwi-interacting RNAs (piRNAs) which silence retrotransposable elements in the genome and regulate DNA methylation, snoRNAs which modify RNAs other than rRNAs, etc. [16-18]. IncRNAs, comprising long or large intergenic ncRNAs (lincRNAs), circular RNAs (circRNAs), etc., are involved in chromatin remodeling, transcriptional regulation, and posttranscriptional processing and thus play important roles in regulating gene expression during development, differentiation, and disease $[16,19,20]$.
Since miRNA is the most widely studied type of ncRNAs, its naming is more orderly. miRNA names include sequential numerical identifiers to distinguish them from each other [21]. Lettered suffixes indicate that the miRNAs differ at only one or two positions in paralogous sequences-for instance, miR-29a, miR-29b, and miR-29c [21]. And " $5 p$ " or "3p" at the end of miRNA names indicate that they are processed from the $5^{\prime}$ and $3^{\prime}$ end arms-for example, miR-142-5p and miR-142-3p [21].

\section{Literature Collection}

The research was carried out in the MEDLINE database (PubMed research engine): ((( (miRNA) OR lncRNA) OR ncRNA) AND ((osteoclast differentiation [tw]) OR (osteoclastogenesis))). This search retrieved 1577 articles. Then, considering that most of the ncRNA researches were carried out after 2008, we narrowed the publish date to January 1,2008, to March 1,2020. We also excluded reviews and added additional filter criteria of language, using the search strategy as follows: $((((($ miRNA) OR lncRNA) OR ncRNA) AND ((osteoclast differentiation [tw]) OR osteoclastogenesis))) NOT “review"[Publication Type]) AND (“2008/01/01"[PDat]: “2020/03/01"[PDat]) AND English [lang]). This search retrieved 1352 articles. Afterwards, we manually assessed the titles and abstracts of the collected articles and excluded those not relevant, which means that the articles are not mainly focused on the relationship between 
ncRNAs and osteoclast differentiation or could not present enough or clear evidence to prove the relationship between them. Finally, we manually added some classical literature and essential articles, which would be helpful for explaining ncRNAs' regulatory roles in osteoclastogenesis.

\section{Involvement of ncRNAs in Osteoclast Differentiation}

The factors that regulate osteoclastogenesis, such as ncRNAs, natural compounds, and epigenetic mechanisms, have been investigated [22]. In vitro experiment showed that the expression levels of 518 lncRNAs, 207 mRNAs, 37 miRNAs, and 24 circRNAs fluctuated during osteoclastogenesis of murine RAW264.7 cells [22], which indicated a role of ncRNAs in the regulation of osteoclastogenesis. For example, osteoclasts cannot be produced from bone marrow HSCs deficient in mature miRNAs [23-26]. Moreover, small interfering RNA- (siRNA-) mediated silencing of the Drosha enzyme complex (which promotes miRNA biosynthesis) or the RNA-induced silencing complex (RISC) (which mediates miRNA binding to its target messenger) blocks osteoclastogenesis [23, 27].

Table 1 summarizes a list of osteoclast-related ncRNAs with validated targets and functions in regulating osteoclastogenesis. Table 2 summarizes a list of ncRNAs implicated in biological events in osteoclasts in in vivo studies.

In the following sections, we will discuss miRNAs and lncRNAs according to their functioning stages in osteoclastogenesis (Figure 2). To our knowledge, ncRNAs and their targets are usually involved in more than one stage of osteoclastogenesis. To give a more accurate network of ncRNAs, we tend to classify the functioning stages of ncRNAs according to their mostly described functions.

3.1. Involvement of ncRNAs in OCP Generation. Osteoclasts are derived from HSCs, which give rise to CMPs, and the latter yield GMPs. GMPs further differentiate into macrophage/osteoclast/dendritic cell precursors, which are known as OCPs [9].

3.1.1. M-CSF, CSF1R, and PU.1. The differentiation from early-stage $\mathrm{CSF}_{1} \mathrm{R}^{-}$osteoclast progenitors to late-stage $\mathrm{CSF}_{1} \mathrm{R}^{+}$OCPs involves various differentiation, proliferation, and antiapoptotic signals. These signals are initiated by $\mathrm{M}-$ CSF produced by the neighboring cells of osteoclasts, including osteoblast and bone marrow stromal cells. M-CSF could induce the proliferation of OCPs, promote cell survival, and upregulate the expression of RANK [28]. In this process, circRNA_28313, miR-195a, and M-CSF together form a circRNA-miRNA-mRNA axis, in which circRNA_28313 relieves miR-195a-mediated suppression on M-CSF by acting as a competing endogenous RNA, therefore modulating osteoclastogenesis of bone marrow-derived macrophages (BMMs) [29].

Besides M-CSF, CSF1R and PU.1 also play key roles in the generation of OCPs. CSF1R could transmit M-CSF signals. And PU.1, which is a member of the Ets family, could regulate CSF1R transcription through Ets-binding sites on a
CSF1R promoter. It was observed that deletion of CSF1R and PU.1 resulted in the lack of both macrophages and osteoclasts [30]. Overexpression of miR-155 suppresses PU.1 expression and activity, resulting in inhibited TRAP expression, osteoclast differentiation, and bone-resorbing activity, as well as repressed mononuclear osteoclast fusion and syncytia formation [31].

3.1.2. IL-15. IL-15 stimulates the differentiation of osteoclast progenitors into OCPs. The possible mechanism might be that IL-15 induces RANKL expression in osteoblasts and stromal cells, indirectly promoting osteoclastogenesis. Moreover, IL-15 is reported to exhibit a synergistic effect with RANKL in osteoclast differentiation by inducing activation of extracellular signal-regulated kinase (ERK), a specific subtype of mitogen-activated protein kinase (MAPK) [32]. As miR-212 negatively targets IL-15, the inhibition of miR-212 gives rise to upregulated IL-15 and thus promotes osteoclastogenesis [33].

3.1.3. IL-11. IL-11 is identified as a necessary factor that promotes osteoclast differentiation. The possible mechanism involves the downstream JAK1/signal transducer and activator of transcription-3 (STAT3) signaling pathway, in which activated STAT3 induces the expression of c-Myc, an important factor in osteoclastogenesis [34]. IL-11 also downregulates GM-CSF expression and sustains the pool of osteoclast progenitors $[32,35]$. During the process of osteoclastogenesis, GM-CSF reveals duration-relevant biphasic effects as it exhibits positive effect on osteoclast proliferation and formation in short-term treatment while it inhibits osteoclastogenesis in long-term treatment [36]. So IL-11 might work as an inhibitor of GM-CSF long-term effect and thus promotes osteoclast differentiation. miR-124 plays a negative role in cancer-induced osteoclast differentiation and activity through targeting IL-11 [37].

3.2. Involvement of ncRNAs in the Early Differentiation of OCPs. During this stage of osteoclastogenesis, the change of OCPs is mainly manifested in the interaction and expression of internal molecules, and more osteoclast-specific molecules are expressed.

3.2.1. RANK/RANKL and Related Molecules. RANK and $\mathrm{CSF} 1 \mathrm{R}$ are both transmembrane signaling receptors required for osteoclast differentiation and activation. RANKL and $\mathrm{M}-\mathrm{CSF}$ bind to and activate RANK and CSF1R, respectively, which initiates the early stage of osteoclastogenesis [10]. Downregulation of miR-503 and miR-144-3p facilitates this stage of osteoclastogenesis by targeting RANK. Conversely, their overexpression inhibits osteoclastogenesis, demonstrated by reduced TRAP staining, decreased TRAP-positive cell numbers, and suppressed expression of osteoclast-specific genes $[38,39]$. Overexpression of IncRNA-NONMMUT037835.2 is also reported to inhibit osteoclastogenesis, as NONMMUT037835.2 could downregulate RANK expression and the subsequent NF- $\kappa \mathrm{B} / \mathrm{MAPK}$ signaling pathway [40].

Like M-CSF, RANKL is also an exogenous regulatory factor for osteoclastogenesis generated from neighboring cells. RANKL exists as a membrane-bound or secreted protein of 
TABLE 1: Major ncRNAs related to biological events in osteoclasts.

\begin{tabular}{|c|c|c|c|c|c|}
\hline miRNA (miR) & Validated target(s) & Functions & Expression & Effect(s) & References \\
\hline lncRNA-LINC00311 & DLL3 & Positive & Not mentioned & $\begin{array}{l}\text { Promotes osteoclast proliferation } \\
\text { and differentiation, shifts cell } \\
\text { cycle distribution, and inhibits apoptosis }\end{array}$ & {$[101]$} \\
\hline lncRNA-AK077216 & Not mentioned & Positive & Upregulated & $\begin{array}{l}\text { Inhibits OCP apoptosis } \\
\text { and promotes osteoclast differentiation, } \\
\text { fusion, bone-resorbing activity, and actin } \\
\text { ring formation }\end{array}$ & {$[98]$} \\
\hline lncRNA-CRNDE & Not mentioned & Positive & Not mentioned & $\begin{array}{l}\text { Promotes osteoclast proliferation and } \\
\text { shifts cell cycle distribution }\end{array}$ & {$[113]$} \\
\hline lncRNA-MAYA & Not mentioned & Positive & Not mentioned & $\begin{array}{l}\text { Promotes osteoclast differentiation } \\
\text { and bone-resorbing activity }\end{array}$ & {$[136]$} \\
\hline lncRNA-MIRG & Not mentioned & Positive & Upregulated & $\begin{array}{c}\text { MIRG inhibition decreases osteoclast } \\
\text { differentiation and bone-resorbing } \\
\text { activity }\end{array}$ & {$[83]$} \\
\hline lncRNA-MALAT1 & Not mentioned & Positive & Not mentioned & $\begin{array}{l}\text { EPC-derived exosomal MALAT1 } \\
\text { promotes osteoclast differentiation } \\
\text { and migration }\end{array}$ & [82] \\
\hline lncRNA-DANCR & Not mentioned & Positive & Not mentioned & $\begin{array}{l}\text { Knockdown of DANCR reduces the } \\
\text { promotion effect of compression force } \\
\text { on osteoclastogenesis }\end{array}$ & {$[104,105]$} \\
\hline lncRNA-TUG1 & Not mentioned & Positive & Not mentioned & $\begin{array}{l}\text { Promotes osteoclast proliferation } \\
\text { and inhibits osteoclast apoptosis }\end{array}$ & {$[112]$} \\
\hline lncRNA-Jak3 & Not mentioned & Positive & Upregulated & $\begin{array}{c}\text { Regulates the Jak3-NFATc1-CTSK axis; } \\
\text { IncRNA-Jak3 knockdown inhibits } \\
\text { osteoclast differentiation and bone- } \\
\text { resorbing activity }\end{array}$ & {$[100]$} \\
\hline circRNA_28313 & Not mentioned & Positive & Upregulated & $\begin{array}{l}\text { circRNA_28313 knockdown inhibits } \\
\text { osteoclastogenesis and actin ring } \\
\text { formation }\end{array}$ & [29] \\
\hline miR-21 & PDCD4, FasL & Positive & Upregulated & $\begin{array}{l}\text { Downregulates PDCD4 and forms a c- } \\
\text { Fos/miR-21/PDCD4 positive feedback } \\
\text { loop and promotes osteoclast } \\
\text { differentiation and bone-resorbing } \\
\text { activity while inhibiting apoptosis }\end{array}$ & $\begin{array}{c}{[23,26,78} \\
117,163,164 \\
185,188-191]\end{array}$ \\
\hline miR-29 & $\begin{array}{l}\text { NFI-A, CALCR, } \\
\text { CDC42, SRGAP2, } \\
\text { GPR85, CD93 }\end{array}$ & Positive & Upregulated & $\begin{array}{l}\text { Promotes osteoclast differentiation, } \\
\text { survival, and bone-resorbing activity }\end{array}$ & $\begin{array}{l}{[78,117,129} \\
190,191]\end{array}$ \\
\hline $\operatorname{miR}-214$ & PTEN & Positive & Upregulated & $\begin{array}{c}\text { Downregulates PTEN and regulates } \\
\text { the PTEN-PI3K-AKT axis, promotes } \\
\text { osteoclast activity, and mediates } \\
\text { osteoclast-osteoblast intercellular } \\
\text { crosstalk }\end{array}$ & $\begin{array}{l}{[108,109,117} \\
190,192]\end{array}$ \\
\hline miR-182 & PKR & Positive & Upregulated & $\begin{array}{l}\text { Downregulates } \mathrm{PKR} \text {, promotes } \\
\text { osteoclast differentiation and bone- } \\
\text { resorbing activity }\end{array}$ & {$[88,115]$} \\
\hline miR-183 & HO-1 & Positive & Upregulated & $\begin{array}{l}\text { Downregulates HO-1, promotes } \\
\text { osteoclastogenesis }\end{array}$ & {$[117,118,190]$} \\
\hline miR-31 & RhoA & Positive & Upregulated & $\begin{array}{l}\text { Negatively regulates RhoA expression at } \\
\text { an appropriate level; miR-31 inhibition } \\
\text { inhibits osteoclast formation, bone- } \\
\text { resorbing activity, and actin ring } \\
\text { formation }\end{array}$ & $\begin{array}{c}{[78,117,139} \\
191]\end{array}$ \\
\hline $\mathrm{miR}-34 \mathrm{c}$ & LGR4 & Positive & Upregulated & $\begin{array}{l}\text { Downregulates LGR4, promotes the } \\
\text { formation of actin rings and TRAP- } \\
\text { positive multinucleated cells }\end{array}$ & {$[97]$} \\
\hline
\end{tabular}


Table 1: Continued.

\begin{tabular}{|c|c|c|c|c|c|}
\hline miRNA (miR) & Validated target(s) & Functions & Expression & Effect(s) & References \\
\hline miR-148a & MAFB & Positive & Upregulated & $\begin{array}{l}\text { Downregulates MAFB, promotes } \\
\text { osteoclastogenesis }\end{array}$ & $\begin{array}{l}{[78,117,123} \\
124,190]\end{array}$ \\
\hline miR-9718 & PIAS3 & Positive & Unregulated & $\begin{array}{c}\text { Downregulates PIAS3, promotes } \\
\text { osteoclastogenesis }\end{array}$ & $\begin{array}{c}{[117,126,127,} \\
190]\end{array}$ \\
\hline miR-483-5p & IGF2 & Positive & Not mentioned & $\begin{array}{l}\text { Downregulates IGF2, promotes } \\
\text { osteoclast differentiation and survival }\end{array}$ & {$[71]$} \\
\hline miR-506 & SIRT1 & Positive & Upregulated & $\begin{array}{l}\text { Downregulates SIRT1; a miR-506 } \\
\text { inhibitor suppresses osteoclastogenesis }\end{array}$ & {$[128]$} \\
\hline miR-363-3p & PTEN & Positive & Upregulated & $\begin{array}{c}\text { Targets PTEN to activate the PI3K/AKT } \\
\text { signaling pathway, promotes } \\
\text { osteoclastogenesis }\end{array}$ & {$[110]$} \\
\hline miR-125a-5p & TNFRSF1B & Positive & Upregulated & $\begin{array}{l}\text { Downregulates TNFRSF1B, promotes } \\
\text { osteoclastogenesis, OCP proliferation, } \\
\text { and growth, migration, and invasion of } \\
\text { RAW264.7 cells }\end{array}$ & {$[66]$} \\
\hline miR-142-5p & PTEN & Positive & Upregulated & $\begin{array}{c}\text { Targets PTEN to activate the PI3K/AKT } \\
\text { signaling pathway, promotes osteoclast } \\
\text { differentiation and activity }\end{array}$ & {$[111]$} \\
\hline miR-199a-5p & MAFB & Positive & Upregulated & $\begin{array}{c}\text { Suppresses MAFB, promotes osteoclast } \\
\text { differentiation }\end{array}$ & {$[125]$} \\
\hline miR-145-5p & OPG & Positive & Not mentioned & $\begin{array}{l}\text { Suppresses OPG, promotes } \\
\text { osteoclastogenesis }\end{array}$ & [49] \\
\hline $\operatorname{miR}-212$ & IL-15, CX3CR1 & Positive & Upregulated & $\begin{array}{l}\text { Downregulates IL-15; miR-212 } \\
\text { inhibition impairs osteoclastogenesis }\end{array}$ & {$[33]$} \\
\hline miR-132 & IRF1 & Positive & Upregulated & $\begin{array}{l}\text { Downregulates IRF1; miR-132 } \\
\text { inhibition impairs osteoclastogenesis }\end{array}$ & {$[33]$} \\
\hline miR-99b & IGF1R & Positive & Upregulated & $\begin{array}{l}\text { Downregulates IGF1R; miR-99b } \\
\text { inhibition impairs osteoclastogenesis }\end{array}$ & {$[33]$} \\
\hline miR-let-7e & $\begin{array}{l}\text { TNFAIP3, ITGA4, } \\
\text { THBS1 }\end{array}$ & Positive & Upregulated & $\begin{array}{c}\text { Downregulates TNFAIP3, ITGA4, and } \\
\text { THBS1; miR-let-7e inhibition impairs } \\
\text { osteoclastogenesis }\end{array}$ & {$[33]$} \\
\hline miR-146a-5p & Not mentioned & Positive & Not mentioned & $\begin{array}{l}\text { miR-146a-5p knockdown impairs } \\
\text { osteoclast differentiation and bone } \\
\text { resorption }\end{array}$ & {$[172]$} \\
\hline $\begin{array}{l}\text { lncRNA- } \\
\text { NONMMUT037835.2 }\end{array}$ & Not mentioned & Negative & Downregulated & Inhibits osteoclastogenesis & {$[40]$} \\
\hline lncRNA-Bmncr & Not mentioned & Negative & Downregulated & $\begin{array}{l}\text { Inhibits osteoclast differentiation } \\
\text { and bone-resorbing activity }\end{array}$ & {$[171]$} \\
\hline $\operatorname{miR}-218$ & $\begin{array}{l}\text { TNFR1, TLR4, } \\
\text { MMP9 }\end{array}$ & Negative & Downregulated & $\begin{array}{l}\text { Inhibits the p38MAPK-c-Fos-NFATc1 } \\
\text { pathway, represses TNFR1, TLR4, and } \\
\text { MMP9, inhibits osteoclastogenesis, cell } \\
\text { migration, actin ring formation, and } \\
\text { bone resorption }\end{array}$ & $\begin{array}{c}{[58,73,86} \\
117,158,190]\end{array}$ \\
\hline $\operatorname{miR}-34 a$ & Tgif2 & Negative & Downregulated & $\begin{array}{c}\text { Downregulates Tgif2, inhibits osteoclast } \\
\text { differentiation and bone-resorbing } \\
\text { activity }\end{array}$ & $\begin{array}{c}{[117,120,190} \\
191]\end{array}$ \\
\hline miR-155 & MITF, Socs1 & Negative & Downregulated & $\begin{array}{l}\text { Downregulates MITF, PU.1, and Socs1, } \\
\text { inhibits osteoclast fusion, differentiation, } \\
\text { and bone-resorbing activity }\end{array}$ & $\begin{array}{l}{[23,31,78,89} \\
90,190,191]\end{array}$ \\
\hline $\mathrm{miR}-7 \mathrm{~b}$ & DC-STAMP & Negative & Downregulated & $\begin{array}{l}\text { Downregulates DC-STAMP, inhibits } \\
\text { osteoclast differentiation and bone- } \\
\text { resorbing activity }\end{array}$ & {$[117,132]$} \\
\hline $\operatorname{miR}-26 a$ & CTGF & Negative & Upregulated & $\begin{array}{l}\text { Downregulates CTGF; inhibits } \\
\text { osteoclastogenesis, actin ring formation, } \\
\text { and bone-resorbing activity }\end{array}$ & {$[117,134,190]$} \\
\hline
\end{tabular}


TABle 1: Continued.

\begin{tabular}{|c|c|c|c|c|c|}
\hline miRNA (miR) & Validated target(s) & Functions & Expression & Effect(s) & References \\
\hline miR-124 & $\begin{array}{l}\text { NFATc1, Rab27a, } \\
\text { IL-11 }\end{array}$ & Negative & Downregulated & $\begin{array}{l}\text { Downregulates NFATc1, Rab27a, and } \\
\text { IL-11, inhibits the proliferation and } \\
\text { motility of OCPs, and decreases } \\
\text { osteoclast differentiation and activity }\end{array}$ & $\begin{array}{c}{[37,78,80} \\
117,166,167 \\
190,191]\end{array}$ \\
\hline $\operatorname{miR}-125 a$ & TRAF6, TNFAIP3 & Negative/positive & $\begin{array}{l}\text { Downregulated/ } \\
\text { upregulated }\end{array}$ & $\begin{array}{c}\text { Inhibited by NFATc1; inhibits osteoclast } \\
\text { differentiation and downregulates } \\
\text { TRAF6; miR-125a inhibition suppresses } \\
\text { osteoclastogenesis and upregulates } \\
\text { TNFAIP3 }\end{array}$ & $\begin{array}{c}{[33,57,78} \\
117,190,191]\end{array}$ \\
\hline miR-146a & TRAF6 & Negative & $\begin{array}{l}\text { Downregulated/ } \\
\text { upregulated }\end{array}$ & $\begin{array}{l}\text { Downregulates TRAF6, inhibits } \\
\text { osteoclastogenesis }\end{array}$ & $\begin{array}{c}{[56,77,78} \\
117,190,191 \\
193,194]\end{array}$ \\
\hline miR-503 & RANK & Negative & Not mentioned & $\begin{array}{l}\text { Downregulates RANK, inhibits } \\
\text { osteoclast differentiation and bone- } \\
\text { resorbing activity }\end{array}$ & $\begin{array}{l}{[38,78,117} \\
190,195]\end{array}$ \\
\hline miR-145 & Smad3 & Negative & Downregulated & $\begin{array}{l}\text { Downregulates Smad3, inhibits } \\
\text { osteoclast differentiation and bone- } \\
\text { resorbing activity }\end{array}$ & {$[60]$} \\
\hline miR-142-3p & $\mathrm{PKC} \alpha$ & Negative & Downregulated & $\begin{array}{l}\text { Downregulates } \mathrm{PKC} \alpha \text {, inhibits osteoclast } \\
\text { clustering, fusion, differentiation, and } \\
\text { survival }\end{array}$ & {$[141]$} \\
\hline $\operatorname{miR}-222-3 p$ & Potential: c-Src & Negative & Downregulated & $\begin{array}{l}\text { Negatively regulates c-Src, inhibits } \\
\text { osteoclast differentiation and bone- } \\
\text { resorbing activity }\end{array}$ & [137] \\
\hline $\operatorname{miR}-340$ & MITF & Negative & Downregulated & $\begin{array}{c}\text { Downregulates MITF, inhibits } \\
\text { osteoclastogenesis }\end{array}$ & {$[121,185]$} \\
\hline miR-16-5p & Not mentioned & Negative & Downregulated & $\begin{array}{l}\text { Inhibits osteoclastogenesis and disrupts } \\
\text { the structure of F-actin rings }\end{array}$ & {$[170]$} \\
\hline $\operatorname{miR}-126-5 p$ & MMP13 & Negative & Not mentioned & $\begin{array}{l}\text { Downregulates MMP13, inhibits } \\
\text { osteoclast differentiation and bone- } \\
\text { resorbing activity }\end{array}$ & {$[159,160]$} \\
\hline miR-17 & $\begin{array}{l}\text { PTP, Vav3 } \\
\text { (potential) }\end{array}$ & Negative & Not mentioned & $\begin{array}{l}\text { miR17/PTP/EphA4 regulatory axis: } \\
\text { decreased miR-17 upregulates PTP, PTP } \\
\text { downregulates EphA4, which activates } \\
\text { osteoclastogenesis; may downregulate } \\
\text { Vav3 and thus inhibits osteoclast fusion }\end{array}$ & {$[140,155,196]$} \\
\hline $\operatorname{miR}-141$ & $\begin{array}{l}\text { MITF, CALCR, } \\
\text { EphA2 }\end{array}$ & Negative & Downregulated & $\begin{array}{c}\text { Downregulates MITF, CALCR, and } \\
\text { EphA2; inhibits osteoclast differentiation } \\
\text { and activity }\end{array}$ & {$[52,55]$} \\
\hline miR-219 & MITF, TRAF6 & Negative & Downregulated & $\begin{array}{l}\text { Downregulates MITF and TRAF6, } \\
\text { inhibits osteoclast differentiation and } \\
\text { activity }\end{array}$ & [55] \\
\hline $\operatorname{miR}-190$ & CALCR & Negative & Downregulated & $\begin{array}{l}\text { Downregulates CALCR, inhibits } \\
\text { osteoclast differentiation and activity }\end{array}$ & {$[55]$} \\
\hline miR-23a & GSK3- $\beta$ & Negative & Downregulated & $\begin{array}{l}\text { Inhibits GSK3- } \beta \text { activation, inhibits } \\
\text { osteoclast differentiation and activity }\end{array}$ & {$[95]$} \\
\hline miR-1225 & Keap1 & Negative & Downregulated & $\begin{array}{l}\text { Downregulates Keap1, inhibits } \\
\text { osteoclast differentiation and activity }\end{array}$ & [119] \\
\hline $\operatorname{miR}-100-5 p$ & FGF21 & Negative & Downregulated & $\begin{array}{l}\text { Downregulates FGF21, inhibits } \\
\text { osteoclastogenesis }\end{array}$ & {$[50]$} \\
\hline $\operatorname{miR}-27 a$ & $\operatorname{PPAR} \gamma, \mathrm{APC}$ & Negative & Not mentioned & $\begin{array}{c}\text { Downregulates PPAR } \gamma \text { and APC, } \\
\text { inhibits osteoclast differentiation and } \\
\text { activity in physiologic condition and } \\
\text { ovariectomized (OVX) mice }\end{array}$ & [84] \\
\hline
\end{tabular}


TABLE 1: Continued.

\begin{tabular}{|c|c|c|c|c|c|}
\hline miRNA (miR) & Validated target(s) & Functions & Expression & Effect(s) & References \\
\hline miR-618 & TLR4 & Negative & Downregulated & $\begin{array}{l}\text { Inhibits osteoclastogenesis via the } \\
\text { TLR4/MyD88/NF- } \kappa \text { B signaling pathway }\end{array}$ & {$[73]$} \\
\hline miR-30a & DC-STAMP & Negative & Downregulated & $\begin{array}{c}\text { Downregulates DC-STAMP, inhibits } \\
\text { osteoclast formation, differentiation, and } \\
\text { activity }\end{array}$ & [133] \\
\hline miR-144-3p & RANK & Negative & Downregulated & $\begin{array}{c}\text { Downregulates RANK, inhibits } \\
\text { osteoclast differentiation, formation, } \\
\text { proliferation, and apoptosis }\end{array}$ & [39] \\
\hline $\operatorname{miR}-9$ & $\mathrm{Cbl}$ & Negative & Not mentioned & $\begin{array}{l}\text { Downregulates } \mathrm{Cbl} \text {, inhibits osteoclast } \\
\text { survival and OCP migration }\end{array}$ & [153] \\
\hline miR-181a & $\mathrm{Cbl}$ & Negative & Not mentioned & $\begin{array}{l}\text { Downregulates } \mathrm{Cbl} \text {, inhibits osteoclast } \\
\text { survival and OCP migration }\end{array}$ & [153] \\
\hline $\operatorname{miR}-29 b$ & BMF & Negative/positive & $\begin{array}{l}\text { Upregulated/ } \\
\text { downregulated }\end{array}$ & $\begin{array}{l}\text { Downregulates BMF; knockdown } \\
\text { impairs osteoclast migration, } \\
\text { commitment, and formation; inhibits } \\
\text { osteoclast differentiation and activity; } \\
\text { enhances osteoclast survival }\end{array}$ & {$[122,129,147]$} \\
\hline $\operatorname{miR}-378$ & Not mentioned & Negative/positive & Upregulated & $\begin{array}{l}\text { Overexpression and underexpression of } \\
\text { miR-378 inhibit osteoclastogenesis }\end{array}$ & {$[55,76-78]$} \\
\hline $\operatorname{miR}-223$ & $\begin{array}{l}\text { NFI-A, IKK } \alpha \\
\quad(\text { potential) }\end{array}$ & Negative/positive & Downregulated & $\begin{array}{l}\text { Promotes osteoclastogenesis by } \\
\text { regulating the relative expression of NFI- } \\
\text { A and CSF1R, downregulates IKK } \alpha \text {, and } \\
\text { inhibits osteoclastogenesis }\end{array}$ & $\begin{array}{c}{[25,27,64,77} \\
78,117,148 \\
150,190]\end{array}$ \\
\hline miR-133a & $\begin{array}{l}\text { MITF, MMP14, } \\
\text { CXCL11, CXCR3, } \\
\text { SLC39A1 }\end{array}$ & Negative/positive & Upregulated & $\begin{array}{l}\text { Downregulates MITF, MMP14, } \\
\text { CXCL11, CXCR3, and SLC39A1; both } \\
\text { positive and negative effects on } \\
\text { osteoclastogenesis are reported }\end{array}$ & $\begin{array}{l}{[55,75,78,92} \\
\quad 117,197]\end{array}$ \\
\hline miR-106b & RANKL & Negative/positive & Not mentioned & $\begin{array}{l}\text { Downregulates RANKL, has different } \\
\text { regulatory roles in CIA bone } \\
\text { microenvironment and giant cell tumor } \\
\text { of bone }\end{array}$ & {$[41,43]$} \\
\hline $\mathrm{miR}-422 \mathrm{a}$ & $\begin{array}{l}\text { Potential: Cbl, } \\
\text { CD226, IGF1, } \\
\text { CBP, TOB2 }\end{array}$ & Positive & Upregulated & $\begin{array}{l}\text { Unclear (probably inhibits those five } \\
\text { inhibitors of osteoclastogenesis) }\end{array}$ & {$[47,78,117]$} \\
\hline miR-338-3p & $\begin{array}{l}\text { IKK } \beta, \text { MAFB, } \\
\text { RANKL }\end{array}$ & Negative/positive & $\begin{array}{l}\text { Upregulated/ } \\
\text { downregulated }\end{array}$ & $\begin{array}{l}\text { Downregulates IKK } \beta, \text { MAFB, and } \\
\text { RANKL; both positive and negative } \\
\text { effects on osteoclastogenesis } \\
\text { are reported }\end{array}$ & {$[42,44,62]$} \\
\hline
\end{tabular}

osteoblasts and activated T cells [11]. miR-106b and miR338-3p weaken osteoclastogenesis by negatively targeting RANKL and are involved in RANKL-RANK signaling [41, 42]. However, the positive effects of miR-106b and miR338-3p are also reported, which may be due to the tissue specificity of osteoclastogenesis $[43,44]$.

Integrin subunit $\alpha 4$ (ITGA4, also known as CD49d), one of the targets of miR-let-7e, is involved in osteoclastogenesis through several indirect ways [33]. Binding of ITGA4 to its receptor increases RANKL production of stromal/osteoprogenitor cells and therefore facilitates osteoclast formation. The interaction with fibronectin is also a possible pathway for ITGA4 to regulate osteoclastogenesis $[45,46]$. miR-let7e negatively targets ITGA4, and inhibited miR-let-7e causes the upregulation of ITGA4. However, inhibited
miR-let-7e is observed to suppress osteoclastogenesis, whose mechanism is still unclear [33]. The possible explanation may be the crosseffect of both the RANKL/RANK pathway and fibronectin.

Additionally, there are some other ncRNAs regulating osteoclastogenesis directly or indirectly by the RANKL/RANK pathway. Transducer of ERBB2, 2 (TOB2), a potential target of miR-422a, is also involved in osteoclast differentiation indirectly as it attenuates RANKL expression in stromal cells $[47,48]$. The upregulation of miR-145-5p increases the expression of RANK and RANKL and supports RANKL-RANK signaling by directly targeting osteoprotegerin (OPG), which can bind to and neutralize RANKL [49]. miR-100-5p suppresses osteoclast differentiation and decreases the expression of osteoclast-specific gene expression, 
TABLE 2: ncRNAs implicated in biological events in osteoclasts in in vivo studies.

\begin{tabular}{|c|c|c|c|c|}
\hline ncRNA & Sample resource(s) & Functions & Effect(s) & References \\
\hline LINC00311 & $\begin{array}{l}\text { OVX mice injected } \\
\text { with LINC00311 } \\
\text { intraperitoneally }\end{array}$ & Positive & $\begin{array}{c}\text { Accelerates osteoclast growth, increases } \\
\text { osteoclast numbers, promotes osteoclast } \\
\text { proliferation, } \\
\text { and inhibits osteoclast apoptosis }\end{array}$ & {$[101]$} \\
\hline MAYA & $\begin{array}{l}\text { MAYA-knockdown mice } \\
\text { (by shRNA or locked nucleic acid) }\end{array}$ & Positive & $\begin{array}{l}\text { Reduces bone lesions and breast cancer } \\
\text { bone tumor burden }\end{array}$ & {$[136]$} \\
\hline MALAT1 & $\begin{array}{c}\text { Femur fracture mice treated with } \\
\text { exosomes derived from EPCs } \\
\text { transfected with MALAT1-targeting } \\
\text { siRNA }\end{array}$ & Positive & $\begin{array}{l}\text { Inhibits osteoclastogenesis and bone } \\
\text { healing }\end{array}$ & {$[82]$} \\
\hline circRNA_28313 & $\begin{array}{l}\text { circRNA_28313-knockdown OVX } \\
\text { mice (Lsh-circRNA_28313-infected) }\end{array}$ & Positive & $\begin{array}{c}\text { Exhibits increased BV/TV, Tb.N, Tb.Th, } \\
\text { and Tb.Sp }\end{array}$ & [29] \\
\hline $\operatorname{miR}-21$ & miR-21-knockout mice & Positive & $\begin{array}{l}\text { Exhibits inhibited bone resorption, } \\
\text { osteoclast differentiation and activity, } \\
\text { and increased bone mass }\end{array}$ & {$[189,198]$} \\
\hline $\operatorname{miR}-214$ & $\begin{array}{l}\text { Osteoclastic miR-214 } \\
\text { transgenic mice }\end{array}$ & Positive & $\begin{array}{c}\text { Exhibits increased osteoclast activity and } \\
\text { bone resorption and reduced bone } \\
\text { mineral density (BMD) }\end{array}$ & {$[109,192,199]$} \\
\hline mir-182 & $\begin{array}{l}\text { (1) } \operatorname{mir}-182^{\text {flox } / \text { llox }} \text { LysMcre }(+) \text { mice } \\
\text { (2) } \operatorname{mir}-182^{+/+} \operatorname{LysMcre}(+) \text { mice }\end{array}$ & Positive & $\begin{array}{c}\text { Compared with (2), (1) exhibits increased } \\
\text { bone mass, connectivity density, BV, } \\
\text { BMD, and Tb.N and decreased trabecular } \\
\text { bone spacing }\end{array}$ & [88] \\
\hline $\operatorname{miR}-148 \mathrm{a}$ & $\begin{array}{l}\text { Silencing of miR-148a with } \\
\text { an antagomir }\end{array}$ & Positive & $\begin{array}{l}\text { Inhibits bone resorption and increases } \\
\text { bone mass }\end{array}$ & {$[124]$} \\
\hline miR-9718 & $\begin{array}{l}\text { Silencing of miR-9718 with an } \\
\text { antagomir in OVX mice and sham- } \\
\text { operated control mice }\end{array}$ & Positive & $\begin{array}{l}\text { Exhibits inhibited bone resorption and } \\
\text { increased bone mass in both OVX mice } \\
\text { and sham-operated control mice }\end{array}$ & {$[127]$} \\
\hline miR-145-5p & $\begin{array}{l}\text { miR-145-5p agomir-treated } \\
\text { collagen-induced arthritis } \\
\text { (CIA) mice }\end{array}$ & Positive & Enhances bone erosion & [49] \\
\hline miR-34a & $\begin{array}{l}\text { (1) miR-34a-knockout and } \\
\text { heterozygous mice } \\
\text { (2) Osteoclastic miR-34a } \\
\text { transgenic mice }\end{array}$ & Negative & $\begin{array}{l}\text { (1) Exhibits increased bone resorption } \\
\text { and reduced bone mass } \\
\text { (2) Exhibits inhibited bone resorption } \\
\text { and increased bone mass }\end{array}$ & {$[120]$} \\
\hline miR-155 & miR- $155^{-/-}$CIA mice & Negative & $\begin{array}{l}\text { Exhibits reduced generation of osteoclasts } \\
\text { and local bone destruction }\end{array}$ & {$[200]$} \\
\hline miR-124 & $\begin{array}{l}\text { (1) Adjuvant-induced arthritis mice } \\
\text { treated with pre-miR-124 } \\
\text { (2) Nude mice transplanted with } \\
\text { MDA-MB-231 cells (breast cancer } \\
\text { cell line) expressing miR-124 }\end{array}$ & Negative & $\begin{array}{l}\text { (1) Exhibits reduced osteoclast numbers } \\
\text { and activity and inhibited osteoclast } \\
\text { differentiation } \\
\text { (2) Inhibits bone metastasis of breast } \\
\text { cancer cells and cancer cell-induced } \\
\text { osteolysis and shows relieved bone lesion }\end{array}$ & {$[37,201]$} \\
\hline miR-146a & CIA mice injected with miR-146a & Negative & $\begin{array}{l}\text { Less osteoclasts at the border of the } \\
\text { pannus and bone }\end{array}$ & {$[56]$} \\
\hline miR-503 & $\begin{array}{l}\text { (1) Silencing of miR-503 with } \\
\text { and antagomir } \\
\text { (2) Overexpression of miR-503 } \\
\text { with agomir }\end{array}$ & Negative & $\begin{array}{l}\text { (1) Increases RANK protein expression } \\
\text { and bone resorption and reduces bone } \\
\text { mass } \\
\text { (2) Inhibits bone resorption and bone loss }\end{array}$ & {$[38]$} \\
\hline miR-145 & $\begin{array}{l}\text { Bilateral OVX-operated mice treated } \\
\text { with a miR-145 agomir }\end{array}$ & Negative & $\begin{array}{l}\text { Attenuates trabecular disconnection and } \\
\text { separation and reverses the increase in the } \\
\text { RANKL to OPG ratio }\end{array}$ & {$[60]$} \\
\hline miR-17 92 & $\begin{array}{l}\text { miR-17 92 osteoclast conditional } \\
\text { knockout mice }\end{array}$ & Negative & $\begin{array}{l}\text { Exhibits decreased connectivity density, } \\
\text { BV/TV, BMD, Tb.N, and Tb.Th } \\
\text { and increased trabecular separation } \\
\text { and bone resorption }\end{array}$ & {$[155]$} \\
\hline
\end{tabular}


TABLE 2: Continued.

\begin{tabular}{|c|c|c|c|c|}
\hline ncRNA & Sample resource(s) & Functions & Effect(s) & References \\
\hline miR-141 & $\begin{array}{l}\text { (1) Mice injected with pre-miR-141 } \\
\text { (2) Nude mice inoculated with } \\
\text { SCP28 cells via intracardiac injection } \\
\text { and then injected with pre-miR-141 } \\
\text { (3) Aged rhesus monkeys with miR- } \\
141 \text { delivery into osteoclasts via a } \\
\text { nucleic acid delivery system }\end{array}$ & Negative & $\begin{array}{l}\text { ((1) and (2)) Exhibits decreased bone } \\
\text { lesions, osteoclast numbers and activity, } \\
\text { and breast cancer bone tumor burden } \\
\text { (3) Exhibits decreased bone erosion and } \\
\text { osteoclast numbers and activity }\end{array}$ & {$[52,55]$} \\
\hline $\operatorname{miR}-219$ & $\begin{array}{l}\text { (1) Mice injected with pre-miR-219 } \\
\text { (2) Nude mice inoculated with } \\
\text { SCP28 cells via intracardiac injection } \\
\text { and then injected with pre-miR-219 }\end{array}$ & Negative & $\begin{array}{l}((1) \text { and }(2)) \text { Exhibits decreased bone } \\
\text { lesions, osteoclast numbers and activity, } \\
\text { and breast cancer bone tumor burden }\end{array}$ & {$[55]$} \\
\hline miR-190 & Mice injected with pre-miR-190 & Negative & Reduces osteoclast activity & {$[55]$} \\
\hline miR-100-5p & $\begin{array}{l}\text { OVX mice treated with agomir- } \\
\text { miR-100-5p }\end{array}$ & Negative & $\begin{array}{l}\text { Decreases osteoclast numbers and the } \\
\text { expression of osteoclast-specific genes }\end{array}$ & {$[50]$} \\
\hline $\operatorname{miR}-27 a$ & $\begin{array}{l}\text { OVX mice injected with miR-27a- } \\
\text { carrying chitosan }\end{array}$ & Negative & $\begin{array}{l}\text { Inhibits osteoclast differentiation and } \\
\text { activity }\end{array}$ & {$[84]$} \\
\hline miR-223 & $\begin{array}{l}\text { CIA mice injected with lentiviral } \\
\text { vectors expressing a miR-223 } \\
\text { target sequence }\end{array}$ & Negative/positive & $\begin{array}{l}\text { Exhibits decreased osteoclastogenesis, } \\
\text { osteoclast numbers and bone erosion, } \\
\text { and relatively intact bone }\end{array}$ & {$[202]$} \\
\hline miR-133a & $\begin{array}{l}\text { Spinal tuberculosis rabbit injected } \\
\text { with notochordal cells containing } \\
\text { miR-133a (1) mimic or } \\
\text { (2) inhibitor } \\
\text { (3) Mice intravenously injected with } \\
\text { pre-miRNA-133a } \\
\text { (4) miR-133a knockdown in } \\
\text { OVX rats by injecting with } \\
\text { antagomiR-133a }\end{array}$ & Negative/positive & $\begin{array}{l}\text { (1) Exhibits reduced osteoclast numbers } \\
\text { (2) Opposite to (1) } \\
\text { (3) Reduces osteoclast activity } \\
\text { (4) Decreases bone erosion and levels of } \\
\text { osteoclastogenesis-related factors in } \\
\text { serum and increases lumbar spine BMD }\end{array}$ & {$[55,92,197]$} \\
\hline miR-106b & $\begin{array}{l}\text { CIA mice injected with } \\
\text { (1) miR-106b mimics or } \\
\text { (2) inhibitor } \\
\text { OVX mice injected with } \\
\text { (3) agomiR-106b or } \\
\text { (4) antagomiR-106b }\end{array}$ & $\begin{array}{l}\text { ((1) and (2)) Positive } \\
((3) \text { and (4)) Negative }\end{array}$ & $\begin{array}{l}\text { (1) Similar to NC } \\
\text { (2) Suppresses bone destruction and } \\
\text { reduces osteoclast numbers and the } \\
\text { RANKL/OPG ratio } \\
\text { (3) Increases BMD and other bone } \\
\text { parameters and decreases osteoclast } \\
\text { formation and activity } \\
\text { (4) Opposite to (3) }\end{array}$ & {$[41,43]$} \\
\hline
\end{tabular}

as well as the protein level of RANK and RANKL, by targeting fibroblast growth factor 21 (FGF21) [50], which is able to alter the RANKL/OPG ratio and promote osteoclastogenesis by indirect effects through other cell types or secreted factors [51].

Ephrin type-A receptor 2 (EphA2) is suggested to be a miR-141 target in rhesus monkey osteoclasts [52]. Excessive expression of EphA2 in OCPs induces osteoclast differentiation. And EphA2 is involved in osteoblast-osteoclast interaction as the ratio of RANKL/OPG decreases in osteoblasts lacking EphA2. There is also some hypothesis that EphA2 may participate in osteoclast autoregulation between osteoclasts at different stages of differentiation [53].

3.2.2. TRAF6/TAB1/TAK1 and Related Molecules. RANKLRANK interaction induces the formation of a complex composed of RANK, tumor necrosis factor receptor-associated factor 6 (TRAF6), transforming growth factor- $\beta$-activated kinase 1-binding protein 1 (TAB1), and transforming growth factor- $\beta$-activated kinase 1 (TAK1). The complex leads to the activation of endogenous TAK1, which stimulates the activation of NF- $\kappa \mathrm{B}$ and its downstream NFATc1 subsequently [54].

Downregulation of miR-125a, miR-219, and miR-146a is reported to promote the early stage of osteoclastogenesis by directly targeting TRAF6, whereas NFATc1 inhibits miR125 a transcription by binding to its promotor region and forms a TRAF6/NFATc1/miR-125a regulatory feedback loop [55-57]. TRAF6 degradation is under regulation of both CX3C chemokine receptor 1 (CX3CR1) and tumor necrosis factor- $\alpha$-induced protein 3 (TNFAIP3). Upregulation of miR-212, miR-125, and miR-let-7e elevates TRAF6 expression as miR-212 targets CX3CR1 and miR-125 and miRlet-7e target TNFAIP3 [33].

Additionally, miR-218 attenuates osteoclastogenesis through targeting tumor necrosis factor receptor 1 (TNFR1), 


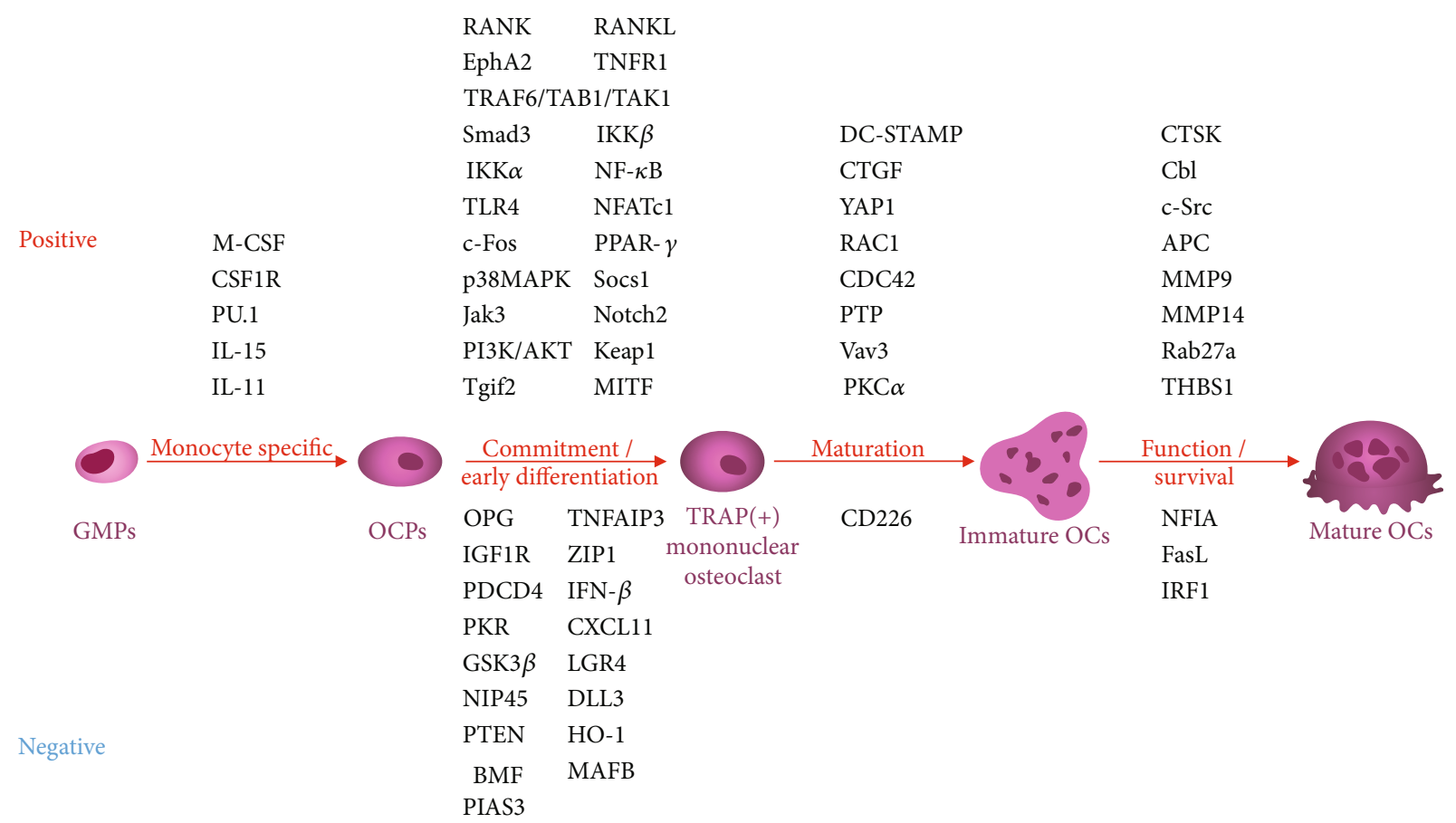

FIGURE 2: Important regulators involved in ncRNAs regulating osteoclastogenesis. ncRNAs function through various regulators to participate in different stages of osteoclastogenesis, including OCP generation, early differentiation, mononuclear osteoclast fusion, and multinucleated osteoclast function and survival. The regulators are positioned by the stage of osteoclastogenesis they are mainly involved in. Positive regulators are listed above the cell figures, while negative regulators are listed below them.

which is involved in the activation of TAK1 and phosphorylated p65 [58]. The TRAF6-TAB1-TAK1 complex also recruits mothers against decapentaplegic homolog $3(\operatorname{Smad} 3)$, which is necessary for the complex formation and downstream signal transduction [59]. Downregulation of miR145, which targets Smad3, augments Smad3 expression and activity. Overexpression of miR-145 suppresses osteoclast differentiation and the expression of markers of osteoclast activity [60].

3.2.3. NF- $\kappa B$ and Related Molecules. NF- $\kappa \mathrm{B}$ is a key regulator of osteoclastogenesis, of which the induction is a hallmark event in the cell fate determination of osteoclasts. In the canonical pathway of NF- $\kappa \mathrm{B}$ activation, TAK1 phosphorylates and activates inhibitor of NF- $\kappa \mathrm{B}$ kinase subunit $\beta$ $(\operatorname{IKK} \beta)$. IKK $\beta$ together with IKK $\alpha$ then phosphorylates and degrades inhibitor of NF- $\kappa \mathrm{B}(\mathrm{I} \kappa \mathrm{B})$, resulting in an NF- $\kappa \mathrm{B}$ dimer entering the nucleus [61].

Downregulation of miR-338-3p accelerates the activation of NF- $\kappa \mathrm{B}$ by targeting IKK $\beta$, and IKK $\alpha$ is reported to be a potential target of miR-223 [62-64]. TNFR2 (encoded by tumor necrosis factor receptor superfamily member $1 \mathrm{~B}$, TNFRSF1B) regulates osteoclastogenesis by transducing intracellular signals which leads to the proteolytic breakdown of $\mathrm{I} \kappa \mathrm{B}$ and the activation of NF- $\kappa \mathrm{B}$ [65]. However, by targeting TNFRSF1B, upregulation of miR-125a-5p inhibits the expression of TNFR2 and promotes osteoclast differentiation, growth, migration, and invasion [66].

Upregulation of miR-99b gives rise to enhanced NF- $\kappa \mathrm{B}$ activity as it is reported to target insulin-like growth factor
1 receptor (IGF1R), whose signaling impedes NF- $\kappa$ B activity $[33,67]$. IGF1, the ligand of IGF1R, is required for normal osteoclast differentiation demonstrated by IGF1 knockout presenting a decreased osteoclast number [68]. IGF1 is also a possible target of miR-422a [47]. IGF2 is a peptide hormone that can modulate osteoclastogenesis through IGF1R activation and may participate in osteoblast-osteoclast interactions $[69,70]$. IGF2 is thought to be the likely target of miR-483-5p promoting osteoclast differentiation and inhibiting apoptosis as miR-483-5p directly inhibits the expression of IGF2 and IGF2 could in turn reverse the effects of miR-483-5p [71].

Toll-like receptor 4 (TLR4), together with myeloid differentiation primary response gene 88 (MyD88), ultimately activates NF- $\kappa \mathrm{B}$ [72]. miR-218 and miR-618 suppress osteoclastogenesis by targeting TLR4 and restraining the TLR4/MyD88/NF- $\kappa$ B signaling pathway [73]. ZIP1, a plasma membrane zinc transporter, impedes both NF- $\kappa \mathrm{B}$ binding activity and osteoclast resorptive activity [74]. Solute carrier family member 1 (SLC39A1), the encoding gene of ZIP1, is a potential target of miR-133a [75]. miR-378 is also involved in the regulation of osteoclastogenesis as both knockdown and overexpression of miR-378 lead to suppressed osteoclast formation. One of the hypothetic molecular mechanisms is that miR-378 is involved in the activation of the NF- $\kappa \mathrm{B}$ signaling pathway through regulating the expression of soluble intracellular adhesion molecule in serum [55, 76-78].

3.2.4. NFATc1 and Related Molecules. NFATc1 is an essential transcription factor for osteoclastogenesis, which is inducted 
mainly through two ways - initial induction and autoamplification. In the initial induction, activated NF- $\kappa$ B is recruited to the NFATc1 promoter and cooperates with NFATc2 to activate the initial induction of NFATc1. The autoamplification refers to RANKL-RANK binding cooperating with immunoreceptors to activate the calcium signals, which induces NFATc1 autoamplification via calcineurin. Activator protein 1 (AP-1, containing c-Fos and c-Jun), which is recruited to the NFATc1 promoter concomitantly, is also critical for this autoamplification [79].

NFATc1 expression and activation are supported by the downregulation of miR-124 as it directly targets NFATc1 $[80,81]$. In the meantime, through the inhibition of miR124, endothelial progenitor cell- (EPC-) derived exosomal lncRNA-MALAT1 induces migration and osteoclastogenesis of BMMs [82]. miR-1897 also targets NFATc1 and downregulates its expression. And lncRNA-MIRG functions as a molecular sponge to modulate the inhibitory effect of miR-1897 on NFATc1 and therefore enhances NFATc1 expression [83].

Downregulation of miR-27a enhances c-Fos activity by targeting peroxisome proliferator-activated receptor $\gamma$ $(\operatorname{PPAR} \gamma)$, a direct regulator of c-Fos expression. The enhanced c-Fos activity then induces NFATc1 autoamplification and thus promotes osteoclastogenesis [84, 85]. Upregulation of miR-21 augments NFATc1 activity by targeting programmed cell death 4 (PDCD4), of which the diminution lifts the repression on $\mathrm{c}$-Fos and forms the c-Fos/miR21/PDCD4 positive feedback loop [23, 26]. Downregulation of miR-218 facilitates NFATc1 activity through the p38MAPK-c-Fos-NFATc1 pathway, as miR-218 inhibits the phosphorylation of $\mathrm{p} 38 \mathrm{MAPK}$ and thus downregulates the expression of NFATc1 and c-Fos $[32,86]$.

Interferon $\beta$ (IFN- $\beta$ ) interferes with the expression of NFATc1 by inhibiting the expression of c-Fos [87]. Upregulation of miR-182 increases NFATc1 activation by targeting protein kinase double-stranded RNA-dependent (PKR), which is a positive regulator of IFN- $\beta$ [88]. miR-155 could suppress NFATc1 activation as it targets suppressor of cytokine signaling 1 (Socs1), a negative regulator of IFN- $\beta$ [89-91]. miR-133a, which potentially targets chemokine (C-X-C motif) ligand 11 (CXCL11) and chemokine (C-X$\mathrm{C}$ motif) receptor 3 (CXCR3), has a positive effect on osteoclastogenesis $[75,92]$. CXCL11, upregulated by IFN- $\beta$, suppresses osteoclast differentiation in a dose-dependent manner and is thought to mediate the regulation of osteoclastogenesis by IFN- $\alpha$ and IFN- $\beta$ [93]. However, CXCR3, the receptor of CXCL11, lacks direct evidence for being involved in osteoclastogenesis.

Glycogen synthase kinase-3 $\beta$ (GSK3- $\beta$ ) is reported to downregulate NFATc1 expression and regulate NFATc1 nuclear localization as GSK3- $\beta$ is capable of blocking NFATc1 transcription and regulating RANKL-induced $\mathrm{Ca}^{2+}$ oscillation-mediated NFATc1 activation [94]. PhosphoGSK3- $\beta$ is the inactive form of GSK3- $\beta$. miR-23a attenuates NFATc1 activity by targeting GSK3- $\beta$ and inhibiting its phosphorylation [95]. Leucine-rich repeat-containing G proteincoupled receptor 4 (LGR4), as a competitor of RANK for RANKL, has the ability to inhibit canonical RANK signaling and activate the GSK3- $\beta$ signaling pathway [96]. Upregula- tion of miR-34c promotes NFATc1 activity by regulating GSK3- $\beta$ signaling via targeting LGR4 [97].

lncRNA-AK077216 promotes the differentiation, fusion, bone resorption, and actin ring formation of osteoclasts while it reduces OCP apoptosis by upregulating NFATc1 through repression of NFAT-interacting protein (NIP45) expression, which is reported to interact with NFATc2 and TRAF6 [98, 99]. IncRNA-Jak3 knockdown inhibits monosodium urate monohydrate- (MSU-) induced osteoclastogenesis and leads to an inhibition of osteoclast bone-resorbing activity, as shown by decreased osteoclast number and pit size. The functional role of $\operatorname{lncRNA-Jak3}$ in osteoclastogenesis is played by Janus kinase 3 (Jak3). lncRNA-Jak3 is coexpressed with Jak3, which positively regulates NFATc1 [100].

IncRNA-LINC00311 has been implicated in osteoclastogenesis by inducing osteoclast proliferation and differentiation while suppressing apoptosis via targeting delta-like 3 (DLL3), whose downregulation activates the Notch signaling pathway. In this way, overexpression of LINC00311 elevates the expression levels of neurogenic locus notch homolog protein 2 (Notch2) and TRAP [101]. Notch2 has been shown to interact with NF- $\kappa \mathrm{B}$, and both of them are recruited to the NFATc1 promoter and enhance the expression of NFATc1 $[102,103]$. The knockdown of IncRNA-DANCR could reduce the promotion effect of compression force on osteoclastogenesis via Jagged 1, a ligand of Notch2. DANCR is also reported to promote the expression of IL- 6 and tumor necrosis factor- $\alpha$ (TNF- $\alpha$ ), of which both have bone-resorbing activity in OCPs $[104,105]$.

3.2.5. ncRNA Targets Involved in the Regulation of Both NF$\kappa B$ and NFATc1. Phosphoinositide 3-kinase (PI3K)/protein kinase $\mathrm{B}$ (AKT) signaling, which is induced by M-CSF binding to CSF1R, could regulate $\mathrm{NF}-\kappa \mathrm{B}$ activity by elevating phosphorylation and subsequent degradation of $\mathrm{I} \kappa \mathrm{B}$ [106]. This signaling pathway could also modulate NFATc1 activity by enhancing the formation of inactive form of GSK3- $\beta$ [107]. Upregulation of miR-214, miR-363-3p, and miR142-5p accelerates PI3K/AKT signaling by targeting phosphatase and tensin homolog (PTEN), which is an inhibitor of PI3K [108-111]. In addition, the excessive expression of lncRNA-TUG1 also gives rise to downregulated PTEN, which may be relevant to the positive effect of TUG1 on osteoclastogenesis [112]. IncRNA-CRNDE also promotes osteoclast proliferation via the $\mathrm{PI} 3 \mathrm{~K} / \mathrm{AKT}$ signaling pathway. Overexpression of CRNDE in osteoclasts significantly decreases the protein levels of p-PI3K, p-AKT, and B cell lymphoma 2 ( $\mathrm{Bcl}-2)$ [113]. AKT also regulates the transcriptional activity of the forkhead box $\mathrm{O}$ (FoxO) family, which counteracts reactive oxygen species (ROS) generation and plays roles in several miRNA pathways in osteoclastogenesis [114]. For example, FoxO3 mediates miR-182 promoting TNF- $\alpha$-induced osteoclastogenesis, and FoxO1 is involved in miR-142-5p promoting osteoclastogenesis [111, 115].

Heme oxygenase (HO-1) deficiency increases the differentiation, survival, and function of osteoclasts by enhancing $\mathrm{I} \kappa \mathrm{B}$ phosphorylation, promoting the production and nuclear translocation of NFATc2, and elevating levels of intracellular calcium and ROS [116]. miR-183 is a member of the miR- 
182-183 miRNA cluster and has highly homologous $5^{\prime}$-seed sequences with miR-182. Upregulation of miR-183 positively regulates osteoclastogenesis by attenuating the expression of HO- 1 at the posttranscriptional level $[117,118]$. Downregulation of miR-1225 potentiates osteoclastogenesis by targeting Keap1 to regulate the Kelch-like ECH-associated protein 1- (Keap1-) nuclear factor erythroid 2-related factor 2- (Nrf2-) HO-1 axis, in which Keap1 overexpression decreases the expression of its downstream proteins, Nrf2 and HO-1 [119].

Transforming growth factor- $\beta$-induced factor 2 (Tgif2) promotes osteoclastogenesis via a positive feedback loop, as NFATc1, c-Jun, and c-Fos activate Tgif2 transcription and Tgif 2 in turn elevates the activity of NFATc1, NF- $\kappa$ B, and c-Jun. Downregulation of miR-34a potentiates osteoclastogenesis by targeting Tgif2, while the overexpression of miR-34a suppresses osteoclastogenesis and bone resorption [120].

3.2.6. Other ncRNA Targets Involved in the Early Differentiation of OCPs. NFATc1, cooperating with AP-1, PU.1, and microphthalmia-associated transcription factor (MITF), generates an osteoclast-specific transcriptional complex and induces the expression of various osteoclast-specific genes, including TRAP, CALCR, CTSK, and osteoclastassociated receptor (OSCAR) [79]. MITF is also thought to be important for the survival of OCPs as it is capable of regulating the antiapoptotic protein Bcl-2 expression in the osteoclast lineage [30]. Downregulation of miR-155, miR-340, miR-141, miR-219, and miR-133a promotes osteoclastogenesis by targeting MITF, and the overexpression of these miRNAs results in decreased expression of osteoclast marker genes and repressed osteoclast differentiation and boneresorbing activity $[31,55,121]$, although the positive effect of miR-133a on osteoclastogenesis is also reported [92]. LPS-induced miR-29b elevates osteoclast survival through targeting and decreasing Bcl-2-modifying factor (BMF), which can bind to $\mathrm{Bcl}-2$ and induce the apoptosis of osteoclasts [122].

$\mathrm{V}$-maf musculoaponeurotic fibrosarcoma oncogene homolog B (MAFB) inhibits osteoclastogenesis by attenuating gene induction of NFATc1 and OSCAR, as well as DNA binding of NFATc1, c-Fos, and MITF, while MAFB also retains the phagocytic activity of BMMs [123]. Upregulation of miR-148a, miR-199a-5p, and miR-338-3p facilitates osteoclastogenesis by targeting MAFB, demonstrated by the increased number of TRAP-positive multinucleated osteoclasts and upregulated expression of osteoclast marker genes $[44,78,124,125]$. Here, miR-338-3p exhibits contradictory effects on osteoclastogenesis as we mentioned above that it inhibits osteoclastogenesis by targeting IKK $\beta$ and RANKL [62].

Protein inhibitor of activated STAT3 (PIAS3) regulates the transcriptional activity of MITF, NFATc1, and c-Fos, resulting in suppressed expression of NFATc1 and OSCAR [126]. Excessive expression of miR-9718 promotes M-CSFand RANKL-induced osteoclast differentiation by targeting PIAS3, while miR-9718 inhibition exerts the opposite effects [127].
Sirtuin 1 (SIRT1) suppresses osteoclast differentiation by inhibiting ROS production as well as transient receptor potential cation channel subfamily V member 1 (TRPV1) activation. Upregulation of miR-506 supports osteoclastogenesis by targeting at $3^{\prime}$-UTR of SIRT1, while a miR-506 inhibitor suppresses osteoclastogenesis demonstrated by TRAP staining, impaired functions, reduced the multinuclear cell number, and downregulated the expression of osteoclast markers and correlated genes [128].

The miR-29 family, including miR-29a, miR-29b, and miR-29c, is also involved in osteoclast lineage commitment as it negatively targets $G$ protein-coupled receptor 85 (GPR85) and CD93, which are promoters of monocyte differentiation into macrophages, and thus interferes with osteoclastogenesis indirectly [129].

\subsection{Involvement of ncRNAs in Mononuclear Osteoclast} Fusion. After the early differentiation, OCPs are committed to the osteoclast lineage and expressing various osteoclastspecific genes, including TRAP. These cells are also known as TRAP-positive mononuclear osteoclasts. These TRAPpositive mononuclear osteoclasts then migrate to each other, make contacts with neighboring cells by membrane protrusion, and subsequently fuse to become multinucleated osteoclasts [130].

3.3.1. DC-STAMP and Related Molecules. Dendritic cellspecific transmembrane protein (DC-STAMP), a downstream gene of NFATc1, is essential for the cell-cell fusion of osteoclasts [30, 131]. Downregulation of miR-7b and miR-30a boosts the fusion of TRAP-positive mononuclear osteoclasts by targeting DC-STAMP and modulating the expression of their downstream fusogenic and regulatory genes $[132,133]$. Inhibition of DC-STAMP by miR-7b also modulates the expression of NFATc1 and OSCAR via the immunoreceptor tyrosine-based activation motif- (ITAM-) immunoreceptor tyrosine-based inhibition motif (ITIM) network [132]. miR-30a overexpression in OCPs suppresses the DC-STAMP/c-Fos/NFATc1 signaling pathway and thus inhibits the formation of osteoclasts, actin ring, and resorbing pit [133]. The overexpression of miR-26a has the same effect as miR-30a, as it targets and downregulates connective tissue growth factor (CTGF), which induces DC-STAMP expression $[134,135]$. IncRNA-MAYA is involved in the regulation of DC-STAMP indirectly as it mediates the activation of yes-associated protein 1 (YAP1), which upregulates CTGF expression, leading to elevated cancer cellinduced osteoclastogenesis and bone resorption [136]. miR-222-3p is also reported to modulate the expression of DC-STAMP [137].

3.3.2. Rho GTPases. The rho family of GTPases, including Ras homolog gene family member A (RhoA), Ras-related C3 botulinum toxin substrate 1 ( $R a c 1$ ), and cell division control protein 42 (CDC42), is involved in various osteoclastogenesis events, such as osteoclast commitment, proliferation, migration, fusion, and maturation [138]. Upregulation of miR-31 could control cytoskeleton organization and support mononuclear osteoclast fusion by targeting RhoA and negatively 
regulating RhoA expression at an appropriate level as both overexpression and suppression of RhoA show a negative effect on osteoclastogenesis [139]. miR-124 may inhibit the expression of RhoA and Racl, leading to reduced mononuclear osteoclast migration [80]. Upregulation of miR-29 is implicated in cytoskeletal organization-involved cell migration by targeting CDC42 and SLIT-ROBO Rho GTPaseactivating protein 2 (SRGAP2), a negative regulator of Rac1 [129]. Downregulation of miR-17 is reported to increase the fusion of osteoclasts possibly via the miR-17-proteintyrosine phosphatase- (PTP-) EphA4 axis or directly targeting vav guanine nucleotide exchange factor 3 (Vav3), thus promoting ITGB3-dependent Vav3-mediated activation of Rac1/Rac2 [140].

3.3.3. PKC $\alpha$. Protein kinase $\mathrm{C} \alpha(\mathrm{PKC} \alpha)$ is involved in cell-tocell contact, clustering, and fusion as it mediates rearrangement of microtubule and actin networks. It is also observed that $\mathrm{PKC} \alpha$ supports cell viability as it regulates antiapoptotic factor Bcl-2. miR-142-3p functions as an inducer of cell death in osteoclasts by targeting PKC $\alpha$. And overexpression of miR-142-3p gives rise to decreased size, viability, and average number of nuclei per cell of osteoclasts [141].

3.3.4. CD226. CD226 is involved in the process of mononuclear osteoclast fusion into multinucleated osteoclasts. It is reported that the formation of multinucleated osteoclasts is impaired when treated with the extracellular domain of CD226, while the formation of TRAP-positive mononuclear osteoclasts is not affected. The promoter of CD226 is regulated by AP-1, which mediates the inhibition effect of NFATc1 on CD226 promoter activity [142]. CD226 is one of the potential targets of miR-422a, and its expression was found to be negatively correlated, albeit not significantly, with that of miR-422a [47].

3.4. Involvement of ncRNAs in Multinucleated Osteoclast Function and Survival. Osteoclasts are polarized when initiating bone resorption. Polarized osteoclasts form three distinct membrane domains: a ruffled border, a sealing zone, and a functional secretory domain. At the sealing zone, the actin cytoskeleton forms an attachment ring and anchors osteoclasts to the bone matrix $[143,144]$. The ruffled border inside the sealing zone consists of distinctive villous-like complexes of the plasma membrane, which harbor massive "spike-like" vacuolar proton pumps [143]. Via these proton pumps, the ruffled membrane transports protons into the resorption compartment to dissolve minerals, while osteoclasts secrete the lytic enzymes TRAP and pro-CTSK to degrade bone matrix proteins [5]. This erodes the underlying bone. The degradation products of collagen and other matrix components are processed in osteoclasts and transported through the cell and exocytosed through the functional secretory domain [144].

3.4.1. CTSK and CALCR. CTSK and CALCR are activated by a transcriptional complex containing NFATc1 and its cooperators including AP-1, p38MAPK, PU.1, and MITF [30, 145]. CTSK is able to degrade type I collagen and regulate osteoclast actin ring formation and therefore influence bone resorption activity [146]. CALCR mediates the antiapoptotic effect of calcitonin on mature osteoclasts, leading to increased osteoclast survival while decreasing their resorption activity [129]. Downregulation of miR-141 and miR190 improves osteoclastogenesis by targeting CALCR [55]. Upregulation of miR-29 increases osteoclast-mediated bone resorption by targeting CALCR [129]. However, it is also reported that miR-29b expression decreases during osteoclast differentiation in vitro, and its overexpression impairs TRAP expression, lacunae generation, and collagen degradation, which are indicators of osteoclast activity [147].

3.4.2. NFI-A. Reduced nuclear factor I/A (NFI-A) expression is essential for the terminal differentiation of osteoclasts, as well as granulocytes and monocytes. Upregulation of miR29 positively regulates osteoclastogenesis by targeting NFIA [129]. NFI-A is also targeted by miR-223 [64]. The role of miR-223 in osteoclastogenesis is still controversial as both of positive and negative effects are mentioned [27, 64, 148, 149]. The expression of miR-223, which is typically downregulated during osteoclastogenesis, is regulated by the competitive binding of NFI-A and CCAAT-enhancer-binding proteins $\alpha(\mathrm{C} / \mathrm{EBP} \alpha)$ to their promoters. NFI-A maintains a low level of miR-223 expression, whereas C/EBP $\alpha$ upregulates miR-223 expression [150]. miR-223 is a component of the PU.1/miR-223/NFI-A/CSF1R positive feedback loop. In this loop, PU.1 expression is induced by M-CSF-stimulated production of pre-miR-223. And PU.1, together with $\mathrm{C} / \mathrm{EBP} \alpha$, stimulates the expression of miR-223 reversely. miR-223 then downregulates NFI-A, leading to the upregulation of CSF1R, which actuates osteoclastogenesis, as well as the expression of PU.1, MITF, and other transcription factors $[23,25,64]$, while in the condition that miR-223 expression is extremely low, its translational repression on NFI-A will be relieved, resulting in blocked osteoclastogenesis [64].

3.4.3. $\mathrm{Cbl}$ and $c$-Src. Osteoclast adhesion and migration involve the tyrosine phosphorylation of casitas B lineage lymphoma ( $\mathrm{Cbl}$ ) and PI3K, as well as the activation of c-Src. Besides its role as an adaptor protein, $\mathrm{Cbl}$ is also a ubiquitin ligase which could target CSF1R and c-Src and regulate the activation of Rac [151, 152]. Downregulated miR-9 and miR-181a promote Cbl expression and activity by targeting $\mathrm{Cbl}$, which is also a potential target of miR-422a [47, 153]. Downregulation of miR-222-3p supports osteoclast adhesion and migration by targeting c-Src, while pit formation activity of multinucleated osteoclasts is decreased by miR-222-3p gain-of-function [137]. CREB-binding protein (CBP, also known as phosphoprotein membrane anchor with glycosphingolipid microdomains 1 (PAG1)), which is also a potential target of miR-422a, inhibits c-Src activity in a dose-dependent manner. Moreover, introduction of CBP leads to suppressed formation of both actin rings and the ruffled border, resulting in decreased bone-resorbing activity $[47,154]$. Downregulation of miR-17 elevates c-Src activation by targeting PTP, which dephosphorylates the inhibitory pY527 of c-Src to activate c-Src signaling. miR-20 and miR92, which are also members of the miR-17 92 cluster genes, also have potential target sites on PTP mRNA, indicating the 
possibility that they play similar negative regulation roles in osteoclastogenesis to that of miR-17 [140, 155].

3.4.4. APC. miR-27a obviously suppresses osteoclast differentiation and activity as miR-27a overexpression markedly disrupts F-actin ring structure and decreases the pit formation of osteoclasts. Adenomatous polyposis coli (APC) is one of the targets of miR-27a, by which miR-27a enhances the inhibitory effect of estrogen on osteoclastogenesis and bone-resorbing activity [84]. APC can stabilize microtubules directly by interacting with microtubules via its microtubulebinding regions or indirectly by interacting with end-binding protein 1 (EB1). Inhibited APC activity gives rise to decreased microtubule stability in osteoclasts, leading to reduced sealing zone formation as well as decreased bone resorption activity. Phosphorylation by GSK-3 $\beta$ decreases the microtubule-binding ability of APC, while AKT enhances APC activity by phosphorylating GSK-3 $\beta$ and decreasing its activity [156].

3.4.5. MMP9. Matrix metalloproteinase 9 (MMP9), which is activated by RANKL stimulation, could promote OCP migration and accelerate osteoclastic resorption via increased degradation of collagen types I and IV [157]. Downregulation of miR-218 augments osteoclastogenesis by negatively targeting MMP9 [158]. MMP13 is also involved in osteoclast differentiation and activation as it is reported to activate preMMP9 and complement the activity of MMP9 in dissolving the bone matrix [159]. miR-126-5p targets MMP13 and represses its expression at a posttranscriptional level to regulate osteoclast differentiation and bone-resorbing activity in a giant cell tumor [160].

3.4.6. MMP14. MMP14 is crucial for osteoclast migration. As a type of secreted MMP, MMP14 is able to regulate osteoclast podosome function, and its collagenolytic activity is thought to be helpful for the osteoclast movement through a collagen fiber network. MMP14-deficient osteoclasts exhibit decreased bone resorption activity [161]. miR-133a targets MMP14 and thus represses osteoclast differentiation and bone-resorbing activity [55].

3.4.7. Fas and FasL. The Fas-Fas ligand (FasL) system, which provides an important apoptotic mechanism for osteoclasts, is activated by FasL binding to a Fas receptor $[67,162]$. miR-21 is involved in the inhibiting and proapoptotic effects of estrogen during osteoclastogenesis as estrogen downregulates miR-21 biogenesis. Decreased miR-21 expression increases the protein levels of FasL, a target of miR-21, and thus induces osteoclastic apoptosis [163]. miR-21 also participates in the regulation of osteoclast differentiation and recruitment in aging bones. Decreased miR-21 levels in aging bones result in osteocyte apoptosis and thus induce osteoclastogenesis by high-mobility group box-1- (HMGB1-) receptor for advanced glycation end product (RAGE) signaling [164]. HMGB1-RAGE signaling plays important roles in regulating actin cytoskeleton reorganization in osteoclasts, thereby participating in RANKL-induced osteoclastogenesis [165]. So miR-21 is also likely to be involved in the regulation of osteoclast bone-resorbing activity.
3.4.8. Rab27a. Rab27a is capable of regulating the transport of lysosome-related organelles and cell surface receptors and thus participating in the modulation of osteoclast bone-resorbing activity. Additionally, Rab27a-deficient osteoclasts display multinucleation, larger cell appearance, and abnormal actin ring formation [166]. miR-124 directly targets Rab27a. Overexpression of miR-124 reduces the protein level of Rab27a, thus inhibiting osteoclastogenesis and impairing the functions of osteoclasts [167].

3.4.9. Other ncRNAs and Their Targets Involved in Osteoclast Function and Survival. Interferon regulatory factor 1 (IRF1), one of the targets of miR-132, suppresses osteoclast maturation and/or activity under the mechanism related to proinflammatory cytokines like IL-12 and IL-18 $[33,168]$.

Thrombospondin 1 (THBS1), a glycoprotein present in a variety of cell types, is one of the targets of miR-let-7e. THBS1 has been identified to be involved in osteoclast-mediated resorption under an undefined mechanism [33, 169].

miR-16-5p suppresses RANKL-induced osteoclastogenesis in a giant cell tumor of bone and disrupts the formation of the F-actin ring, which is essential for osteoclast boneresorbing activity. However, the direct target of miR-16-5p functioning is undefined [170].

\subsection{Involvement of ncRNAs with Undefined Targets and Functioning Stages}

3.5.1. IncRNA-Bmncr. The expression of lncRNA-Bmncr gradually decreases during RANKL-induced osteoclastogenesis, which reaches the lowest level at $72 \mathrm{~h}$. The overexpression of Bmncr reduces osteoclast numbers and bone-resorbing capacity and decreases the expression of osteoclast-specific genes, while knockdown of Bmncr has opposite effects [171].

3.5.2. $m i R-146 a-5 p$. Compared with psoriasis patients without arthritis and normal controls, miR-146a-5p expression is higher in peripheral $\mathrm{CD} 14^{+}$monocytes from patients with psoriatic arthritis. miR-146-5p induces osteoclast activation and bone-resorbing activity as shown by miR-146a-5p knockdown revealing a decreased generated osteoclast number and impaired bone resorption [172].

3.5.3. Enhancer RNAs. Enhancer RNAs (eRNAs) are a kind of lncRNA present in the $5^{\prime}$-flanking regions or intronic regions of genes which initiate bidirectional RNA biosynthesis and are involved in the differentiation of various cell types $[173,174]$. Deletion of the eRNA regions of neuropilin 2, DC-STAMP, and NFATc1 significantly inhibits the formation of TRAP-positive multinucleated cells, indicating that their expression positively regulates osteoclastogenesis. And eRNAs also functions by increasing the expression of RNAs encoding osteoclast-related proteins [173].

\section{Discussion}

Bone remodeling involves various biological events of osteoblasts and osteoclasts, all of which are regulated by a precise network of systemic and local factors, including ncRNAs 
$[175,176]$. When the network is unable to compensate for the difference between bone resorption and synthesis, unbalanced bone remodeling will cause diseases [177]. As a kind of ncRNAs with numerous numbers, miRNAs downregulate gene expression by either of two posttranscriptional ways: mRNA cleavage or translational repression. The former one occurs when the mRNA has sufficient complementarity to the miRNA; otherwise, the latter one occurs [178]. The way lncRNAs work is mainly through the interaction with miRNAs as molecular sponges [179].

Most studies of the functions of ncRNAs in the regulation of osteoclast activity have focused on ncRNA expression levels, the effects of ncRNA mimics/inhibitors, and ncRNA target genes. Apart from osteoclast pathological experiments, RAW264.7 cells and BMMs have been the most frequently used sources of osteoclasts in such studies. RAW264.7 is a mouse monocyte macrophage leukemia cell line developed by injection of Abelson leukemia virus [180]. BMMs are produced by culturing nonadherent bone marrow cells from the femur and tibia in the presence of M-CSF [181]. The J774 and U-937 cell lines have also been used to generate osteoclasts [180]. Reverse transcription quantitative polymerase chain reaction (RT-qPCR) analysis is one of the most frequently used methods for analyzing the gene expression levels of ncRNAs and osteoclastspecific genes [58, 97, 101, 180,182, 183]. Microarray analysis is also widely used for detecting gene expression levels, as well as identifying novel regulators of osteoclastogenesis $[141,184]$. Microcomputed tomography enables the assessment of the structural parameters involved, such as bone volume per total volume (BV/TV), mean trabecular number (Tb.N), mean trabecular thickness (Tb.Th), and trabecular separation (Tb.Sp) [43, 180, 185]. Immunoblotting, as well as qualitative and semiquantitative analyses, is extensively used for the detection and characterization of proteins [186]. Chromatin immunoprecipitation (ChIP) enables the analysis of interactions between proteins and DNA in chromosomal fragments and the identification of the binding sites of transcription factors and other proteins [180, 187]. Additionally, four web-based miRNA databases, miRBase (http://www.mirbase.org), TargetScan (http://www.targetscan. org), PicTar (http://www.pictar.mdc-berlin.de), and miRanda (http://www.microRNA.org), are essential for bioinformatics analysis [108]. Assays of pit formation, actin ring formation, cell migration, macrophage commitment, and apoptosis are also widely used to evaluate the functions and generation of osteoclasts [86, 98, 115, 129, 147, 153].

\section{Conclusion}

With the profound research in bone physiology and diseases related to bone metabolism disorder, the essential role of ncRNAs in osteoclastogenesis is gradually recognized. In this review, we summarized the current knowledge of ncRNAs involved in important osteoclast differentiation events, including OCP generation, early differentiation, mononuclear osteoclast fusion, and multinucleated osteoclast function and survival. Nevertheless, there are still some unknown mechanisms for ncRNAs regulating osteoclast dif- ferentiation, and further work is needed to supplement and perfect the effects of ncRNAs, particularly those of lncRNAs, circRNAs, and eRNAs, on the functions of osteoclasts.

\section{Abbreviations}

Protein kin

AP-1: $\quad$ Activator protein 1

APC: Adenomatous polyposis coli

Bcl-2: $\quad$ B cell lymphoma 2

BMD: $\quad$ Bone mineral density

BMF: $\quad$ Bcl-2-modifying factor

BMMs: $\quad$ Bone marrow-derived macrophages

BV/TV: $\quad$ Bone volume per total volume

$\mathrm{C} / \mathrm{EBP} \alpha$ : CCAAT-enhancer-binding proteins $\alpha$

CALCR: Calcitonin receptor

Cbl: $\quad$ Casitas B lineage lymphoma

CBP: $\quad$ CREB-binding protein

CDC42: $\quad$ Cell division control protein 42

ChIP: Chromatin immunoprecipitation

CIA: Collagen-induced arthritis

circRNAs: Circular RNAs

CMPs: Common myeloid progenitors

CSF1R: Colony-stimulating factor 1 receptor

CTGF: Connective tissue growth factor

CTSK: Cathepsin K

CX3CR1: $\quad$ CX3C chemokine receptor 1

CXCL11: Chemokine (C-X-C motif) ligand 11

CXCR3: $\quad$ Chemokine (C-X-C motif) receptor 3

DC-STAMP: Dendritic cell-specific transmembrane protein

DLL3: $\quad$ Delta-like 3

EB1: $\quad$ End-binding protein 1

EPC: $\quad$ Endothelial progenitor cells

EphA: $\quad$ Ephrin type-A receptor

ERK: $\quad$ Extracellular signal-regulated kinase

eRNA: $\quad$ Enhancer RNA

FasL: $\quad$ Fas ligand

FGF21: $\quad$ Fibroblast growth factor 21

Foxo: $\quad$ Forkhead box $\mathrm{O}$

GMPs: Granulocyte/macrophage progenitors

GPR85: $\quad$ G protein-coupled receptor 85

GSK3- $\beta$ : $\quad$ Glycogen synthase kinase $3-\beta$

HER3: Human epidermal growth factor receptor 3

HMGB1: High-mobility group box-1

HO-1: Heme oxygenase

HSCs: Hematopoietic stem cells

IFN: Interferon

IGF1: Insulin-like growth factor 1

I $\kappa \mathrm{B}: \quad$ Inhibitor of nuclear factor $\kappa \mathrm{B}$

IKK: $\quad$ Inhibitor of nuclear factor $\kappa \mathrm{B}$ kinase subunit

IRF1: $\quad$ Interferon regulatory factor 1

ITAM: Immunoreceptor tyrosine-based activation motif

ITGA4: $\quad$ Integrin subunit $\alpha 4$

ITGB3: $\quad$ Integrin $\beta 3$

ITIM: Immunoreceptor tyrosine-based inhibition motif

Jak3: Janus kinase 3

Keap1: Kelch-like ECH-associated protein 1 
LGR4: Leucine-rich repeat-containing G proteincoupled receptor 4

lincRNAs: $\quad$ Long or large intergenic ncRNAs

lncRNAs: $\quad$ Long noncoding RNAs

MAFB: $\quad$ V-maf musculoaponeurotic fibrosarcoma oncogene homolog B

Maml1:

MAPK:

M-CSF:

miRNAs:

MITF:

MMP:

MSU:

MyD88:

ncRNAs:

NFATc1:

NFI-A:

NF- $\kappa$ B:

NIP45:

Notch2:

Nrf2:

OCPs:

OPG:

OSCAR:

OVX:

PAG1:

PDCD4:

PI3K:

PIAS3:

piRNAs:

$\mathrm{PKC} \alpha$ :

PKR:

PPAR $\gamma$ :

PTEN:

PTP:

Rac:

RAGE:

RANK:

RANKL:

RhoA:

RISC:

ROR1:

ROS:

RT-qPCR

SCF:

siRNAs:

SIRT1:

Smad3:

snoRNAs:

Socs1:

SRGAP2:

STAT3:
TAB1: $\quad$ Transforming growth factor- $\beta$-activated kinase 1-binding protein 1

TAK1: $\quad$ Transforming growth factor- $\beta$-activated kinase 1

Tb.N: $\quad$ Trabecular number

Tb.Sp: $\quad$ Trabecular separation

Tb.Th: $\quad$ Trabecular thickness

Tgif2: $\quad$ Transforming growth factor- $\beta$-induced factor 2

THBS1: $\quad$ Thrombospondin 1

TLR4: $\quad$ Toll-like receptor 4

TNF- $\alpha$ : $\quad$ Tumor necrosis factor- $\alpha$

TNFAIP3: $\quad$ Tumor necrosis factor- $\alpha$-induced protein 3

TNFR: Tumor necrosis factor receptor

TNFRSF1B: Tumor necrosis factor receptor superfamily member $1 \mathrm{~B}$

TOB2: $\quad$ Transducer of ERBB2, 2

TRAF6: $\quad$ Tumor necrosis factor receptor-associated factor 6

TRAP: $\quad$ Tartrate-resistant acid phosphatase

TRPV1: $\quad$ Transient receptor potential cation channel subfamily $\mathrm{V}$ member 1

Vav3: $\quad$ Vav guanine nucleotide exchange factor 3

YAP1: $\quad$ Yes-associated protein 1.

\section{Conflicts of Interest}

All authors have no conflicts of interest.

\section{Authors' Contributions}

Yi Zhao and Yunfei Zheng conceived and designed the study strategy. Lingfei Jia was responsible for the reference collection. Yi Zhao wrote the manuscript and prepared the tables and figures. Yunfei Zheng reviewed and edited the manuscript. Weiran Li and Yunfei Zheng were responsible for the study supervision. All authors reviewed the manuscript.

\section{Acknowledgments}

This study was financially supported by grants from the National Natural Science Foundation of China (Nos. 81700938, 81670957, and 81772876), the Beijing Natural Science Foundation (No. 7172239), and the Fund for Fostering Young Scholars of Peking University Health Science Center (BMU2018PY022).

\section{References}

[1] Y. C. Guo, S. W. Zhang, and Q. Yuan, "Deubiquitinating enzymes and bone remodeling," Stem Cells International, vol. 2018, Article ID 3712083, 9 pages, 2018.

[2] S. J. Noxon, G. J. King, G. Gu, and G. Huang, "Osteoclast clearance from periodontal tissues during orthodontic tooth movement," American Journal of Orthodontics and Dentofacial Orthopedics, vol. 120, no. 5, pp. 466-476, 2001.

[3] W. J. Rody, G. J. King, and G. Gu, "Osteoclast recruitment to sites of compression in orthodontic tooth movement," American Journal of Orthodontics and Dentofacial Orthopedics, vol. 120, no. 5, pp. 477-489, 2001. 
[4] S. C. Manolagas and R. L. Jilka, "Bone marrow, cytokines, and bone remodeling-emerging insights into the pathophysiology of osteoporosis," New England Journal of Medicine, vol. 332, no. 5, pp. 305-311, 1995.

[5] W. J. Boyle, W. S. Simonet, and D. L. Lacey, "Osteoclast differentiation and activation," Nature, vol. 423, no. 6937, pp. 337-342, 2003.

[6] K. Henriksen, J. Bollerslev, V. Everts, and M. A. Karsdal, "Osteoclast activity and subtypes as a function of physiology and pathology-implications for future treatments of osteoporosis," Endocrine Reviews, vol. 32, no. 1, pp. 31-63, 2011.

[7] G. Schett and S. L. Teitelbaum, "Osteoclasts and arthritis," Journal of Bone and Mineral Research, vol. 24, no. 7, pp. 1142-1146, 2009.

[8] K. N. Weilbaecher, T. A. Guise, and L. K. McCauley, "Cancer to bone: a fatal attraction," Nature Reviews Cancer, vol. 11, no. 6, pp. 411-425, 2011.

[9] F. Xu and S. L. Teitelbaum, "Osteoclasts: new insights," Bone Research, vol. 1, no. 1, pp. 11-26, 2013.

[10] S. Uehara, N. Udagawa, and Y. Kobayashi, "Non-canonical Wnt signals regulate cytoskeletal remodeling in osteoclasts," Cellular and Molecular Life Sciences, vol. 75, no. 20, pp. 3683-3692, 2018.

[11] B. F. Boyce and L. Xing, "Functions of RANKL/RANK/OPG in bone modeling and remodeling," Archives of Biochemistry and Biophysics, vol. 473, no. 2, pp. 139-146, 2008.

[12] J. Mattick and I. V. Makunin, "Non-coding RNA," Human Molecular Genetics, vol. 15, Supplement 1, pp. R17-R29, 2006.

[13] T. Gutschner and S. Diederichs, "The hallmarks of cancer," RNA Biology, vol. 9, no. 6, pp. 703-719, 2014.

[14] E. A. Gibb, C. J. Brown, and W. L. Lam, "The functional role of long non-coding RNA in human carcinomas," Molecular Cancer, vol. 10, no. 1, p. 38, 2011.

[15] C. Gao, S. Peng, P. Feng, and C. Shuai, "Bone biomaterials and interactions with stem cells," Bone Research, vol. 5, no. 1, article 17059, 2017.

[16] A. E. Kornienko, P. M. Guenzl, D. P. Barlow, and F. M. Pauler, "Gene regulation by the act of long non-coding RNA transcription," BMC Biology, vol. 11, no. 1, p. 59, 2013.

[17] F. F. Costa, "Non-coding RNAs: meet thy masters," Bioessays, vol. 32, no. 7, pp. 599-608, 2010.

[18] S. R. Eddy, "Noncoding RNA genes," Current Opinion in Genetics \& Development, vol. 9, no. 6, pp. 695-699, 1999.

[19] M. Dahl, L. S. Kristensen, and K. Grønbæk, "Long noncoding RNAs guide the fine-tuning of gene regulation in Bcell development and malignancy," International Journal of Molecular Sciences, vol. 19, no. 9, p. 2475, 2018.

[20] S. Geisler and J. Coller, "RNA in unexpected places: long noncoding RNA functions in diverse cellular contexts," Nature Reviews Molecular Cell Biology, vol. 14, no. 11, pp. 699-712, 2013.

[21] S. Griffiths-Jones, R. J. Grocock, S. van Dongen, A. Bateman, and A. J. Enright, "miRBase: microRNA sequences, targets and gene nomenclature," Nucleic Acids Research, vol. 34, no. 90001, pp. D140-D144, 2006.

[22] C. Dou, Z. Cao, B. Yang et al., "Changing expression profiles of lncRNAs, mRNAs, circRNAs and miRNAs during osteoclastogenesis," Scientific Reports, vol. 6, no. 1, article 21499, 2016.
[23] J. B. Lian, G. S. Stein, A. J. van Wijnen et al., "MicroRNA control of bone formation and homeostasis," Nature Reviews Endocrinology, vol. 8, no. 4, pp. 212-227, 2012.

[24] F. Mizoguchi, Y. Izu, T. Hayata et al., "Osteoclast-specific Dicer gene deficiency suppresses osteoclastic bone resorption," Journal of Cellular Biochemistry, vol. 109, pp. 866$875,2009$.

[25] T. Sugatani and K. A. Hruska, "Impaired micro-RNA pathways diminish osteoclast differentiation and function," Journal of Biological Chemistry, vol. 284, no. 7, pp. 4667-4678, 2009.

[26] T. Sugatani, J. Vacher, and K. A. Hruska, "A microRNA expression signature of osteoclastogenesis," Blood, vol. 117, no. 13, pp. 3648-3657, 2011.

[27] T. Sugatani and K. A. Hruska, "MicroRNA-223 is a key factor in osteoclast differentiation," Journal of Cellular Biochemistry, vol. 101, no. 4, pp. 996-999, 2007.

[28] L. Xing, E. M. Schwarz, and B. F. Boyce, "Osteoclast precursors, RANKL/RANK, and immunology," Immunological Reviews, vol. 208, no. 1, pp. 19-29, 2005.

[29] X. Chen, Z. Ouyang, Y. Shen et al., “CircRNA_28313/miR195a/CSF1 axis modulates osteoclast differentiation to affect OVX-induced bone absorption in mice," RNA Biology, vol. 16, no. 9, pp. 1249-1262, 2019.

[30] M. Asagiri and H. Takayanagi, "The molecular understanding of osteoclast differentiation," Bone, vol. 40, no. 2, pp. 251-264, 2007.

[31] M. Mann, O. Barad, R. Agami, B. Geiger, and E. Hornstein, "miRNA-based mechanism for the commitment of multipotent progenitors to a single cellular fate," Proceedings of the National Academy of Sciences of the United States of America, vol. 107, no. 36, pp. 15804-15809, 2010.

[32] D. S. Amarasekara, H. Yun, S. Kim, N. Lee, H. Kim, and J. Rho, "Regulation of osteoclast differentiation by cytokine networks," Immune Network, vol. 18, no. 1, article e8, 2018.

[33] L. de la Rica, A. García-Gómez, N. R. Comet et al., "NF- $\kappa$ Bdirect activation of microRNAs with repressive effects on monocyte-specific genes is critical for osteoclast differentiation," Genome Biology, vol. 16, no. 1, 2015.

[34] M. Liang, Q. Ma, N. Ding et al., "IL-11 is essential in promoting osteolysis in breast cancer bone metastasis via RANKLindependent activation of osteoclastogenesis," Cell Death \& Disease, vol. 10, no. 5, p. 353, 2019.

[35] E. M. McCoy, H. Hong, H. C. Pruitt, and X. Feng, "IL-11 produced by breast cancer cells augments osteoclastogenesis by sustaining the pool of osteoclast progenitor cells," BMC Cancer, vol. 13, no. 1, article 16, 2013.

[36] J. M. Hodge, M. A. Kirkland, C. J. Aitken et al., "Osteoclastic potential of human CFU-GM: biphasic effect of GM-CSF," Journal of Bone and Mineral Research, vol. 19, no. 2, pp. 190-199, 2004.

[37] W. L. Cai, W. D. Huang, B. Li et al., "MicroRNA-124 inhibits bone metastasis of breast cancer by repressing Interleukin11," Molecular Cancer, vol. 17, no. 1, p. 9, 2018.

[38] C. Chen, P. Cheng, H. Xie et al., "miR-503 regulates osteoclastogenesis via targeting RANK," Journal of Bone and Mineral Research, vol. 29, no. 2, pp. 338-347, 2014.

[39] C. Wang, H. He, L. Wang, Y. Jiang, and Y. Xu, "Reduced miR-144-3p expression in serum and bone mediates osteoporosis pathogenesis by targeting RANK," Biochemistry and Cell Biology, vol. 96, no. 5, pp. 627-635, 2018. 
[40] Y. Chang, D. Yu, W. Chu, Z. Liu, H. Li, and Z. Zhai, "IncRNA expression profiles and the negative regulation of lncRNANOMMUT037835.2 in osteoclastogenesis," Bone, vol. 130, article 115072, 2020.

[41] T. Wang, H. Yin, J. Wang et al., "MicroRNA-106b inhibits osteoclastogenesis and osteolysis by targeting RANKL in giant cell tumor of bone," Oncotarget, vol. 6, no. 22, pp. 18980-18996, 2015.

[42] X. H. Zhang, G. L. Geng, B. Su, C. P. Liang, F. Wang, and J. C. Bao, "MicroRNA-338-3p inhibits glucocorticoid-induced osteoclast formation through RANKL targeting," Genetics and Molecular Research, vol. 15, no. 3, 2016.

[43] Y. Tao, Z. Wang, L. Wang et al., "Downregulation of miR$106 \mathrm{~b}$ attenuates inflammatory responses and joint damage in collagen-induced arthritis," Rheumatology, vol. 56, no. 10, pp. 1804-1813, 2017.

[44] Q. Sun, B. Zhang, W. Zhu, W. Wei, J. Ma, and F. R. Tay, “A potential therapeutic target for regulating osteoporosis via suppression of osteoclast differentiation," Journal of Dentistry, vol. 82, pp. 91-97, 2019.

[45] M. Bolzoni, P. Storti, S. Bonomini et al., "Immunomodulatory drugs lenalidomide and pomalidomide inhibit multiple myeloma-induced osteoclast formation and the RANKL/OPG ratio in the myeloma microenvironment targeting the expression of adhesion molecules," Experimental Hematology, vol. 41, no. 4, pp. 387-397.e1, 2013.

[46] M. Colombo, D. Giannandrea, E. Lesma, A. Basile, and R. Chiaramonte, "Extracellular vesicles enhance multiple myeloma metastatic dissemination," International Journal of Molecular Sciences, vol. 20, no. 13, p. 3236, 2019.

[47] Z. Cao, B. T. Moore, Y. Wang et al., "miR-422a as a potential cellular microRNA biomarker for postmenopausal osteoporosis," PLoS One, vol. 9, no. 5, article e97098, 2014.

[48] R. Ajima, T. Akiyama, M. Usui et al., "Osteoporotic bone formation in mice lacking tob2; involvement of Tob2 in RANK ligand expression and osteoclasts differentiation," FEBS Letters, vol. 582, no. 9, pp. 1313-1318, 2008.

[49] Y. Chen, X. Wang, M. Yang et al., "miR-145-5p increases osteoclast numbers in vitro and aggravates bone erosion in collagen-induced arthritis by targeting osteoprotegerin," Medical Science Monitor, vol. 24, pp. 5292-5300, 2018.

[50] L. Zhou, H.-. Y. Song, L.-. L. Gao, L.-. Y. Yang, S. Mu, and Q. Fu, "MicroRNA-100-5p inhibits osteoclastogenesis and bone resorption by regulating fibroblast growth factor 21 ," International Journal of Molecular Medicine, vol. 43, pp. 727-738, 2018.

[51] W. Wei, P. A. Dutchak, X. Wang et al., "Fibroblast growth factor 21 promotes bone loss by potentiating the effects of peroxisome proliferator-activated receptor," Proceedings of the National Academy of Sciences of the United States of America, vol. 109, no. 8, pp. 3143-3148, 2012.

[52] S. Yang, W. Zhang, M. Cai et al., "Suppression of bone resorption by miR-141 in aged rhesus monkeys," Journal of Bone and Mineral Research, vol. 33, no. 10, pp. 1799-1812, 2018.

[53] N. Irie, Y. Takada, Y. Watanabe et al., "Bidirectional signaling through ephrinA2-EphA2 enhances osteoclastogenesis and suppresses osteoblastogenesis," Journal of Biological Chemistry, vol. 284, no. 21, pp. 14637-14644, 2009.

[54] J. Mizukami, G. Takaesu, H. Akatsuka et al., "Receptor activator of NF- $\kappa$ B ligand (RANKL) activates TAK1 mitogen- activated protein kinase kinase kinase through a signaling complex containing RANK, TAB2, and TRAF6," Molecular and Cellular Biology, vol. 22, no. 4, pp. 992-1000, 2002.

[55] B. Ell, L. Mercatali, T. Ibrahim et al., "Tumor-induced osteoclast miRNA changes as regulators and biomarkers of osteolytic bone metastasis," Cancer Cell, vol. 24, no. 4, pp. 542-556, 2013.

[56] T. Nakasa, H. Shibuya, Y. Nagata, T. Niimoto, and M. Ochi, "The inhibitory effect of microRNA-146a expression on bone destruction in collagen-induced arthritis," Arthritis and Rheumatism, vol. 63, no. 6, pp. 1582-1590, 2011.

[57] L.-J. Guo, L. Liao, L. Yang, Y. Li, and T.-J. Jiang, "miR-125a TNF receptor-associated factor 6 to inhibit osteoclastogenesis," Experimental Cell Research, vol. 321, no. 2, pp. 142152, 2014.

[58] W. Wang, L. Yang, D. Zhang et al., "MicroRNA-218 negatively regulates osteoclastogenic differentiation by repressing the nuclear factor- $\kappa \mathrm{B}$ signaling pathway and targeting tumor necrosis factor receptor 1," Cellular Physiology and Biochemistry, vol. 48, no. 1, pp. 339-347, 2018.

[59] T. Yasui, Y. Kadono, M. Nakamura et al., "Regulation of RANKL-induced osteoclastogenesis by TGF- $\beta$ through molecular interaction between Smad3 and Traf6," Journal of Bone and Mineral Research, vol. 26, no. 7, pp. 1447-1456, 2011.

[60] F.-y. Yu, C.-q. Xie, J.-t. Sun, W. Peng, and X.-w. Huang, "Overexpressed miR-145 inhibits osteoclastogenesis in RANKL-induced bone marrow-derived macrophages and ovariectomized mice by regulation of Smad3," Life Sciences, vol. 202, pp. 11-20, 2018.

[61] Z. J. Chen, "Ubiquitin signalling in the NF- $\kappa \mathrm{B}$ pathway," Nature Cell Biology, vol. 7, no. 8, pp. 758-765, 2005.

[62] D. Niu, Z. Gong, X. Sun et al., "miR-338-3p regulates osteoclastogenesis via targeting IKK $\beta$ gene," In Vitro Cellular \& Developmental Biology - Animal, vol. 55, no. 4, pp. 243-251, 2019.

[63] T. Li, M. J. Morgan, S. Choksi, Y. Zhang, Y. S. Kim, and Z. G. Liu, "MicroRNAs modulate the noncanonical transcription factor NF- $\kappa$ B pathway by regulating expression of the kinase IKK $\alpha$ during macrophage differentiation," Nature Immunology, vol. 11, no. 9, pp. 799-805, 2010.

[64] Y. Xie, L. Zhang, Y. Gao, W. Ge, and P. Tang, "The multiple roles of microrna-223 in regulating bone metabolism," Molecules, vol. 20, no. 10, pp. 19433-19448, 2015.

[65] S. D. Yogesha, S. M. Khapli, and M. R. Wani, "Interleukin-3 and granulocyte-macrophage colony-stimulating factor inhibits tumor necrosis factor (TNF)- $\alpha$-induced osteoclast differentiation by down-regulation of expression of TNF receptors 1 and 2," Journal of Biological Chemistry, vol. 280, no. 12, pp. 11759-11769, 2005.

[66] L. Sun, J. X. Lian, and S. Meng, "miR-125a-5p promotes osteoclastogenesis by targeting TNFRSF1B," Cellular \& Molecular Biology Letters, vol. 24, no. 1, p. 23, 2019.

[67] H. C. Hrdlicka, S. K. Lee, and A. M. Delany, "MicroRNAs are critical regulators of osteoclast differentiation," Current Molecular Biology Reports, vol. 5, no. 1, pp. 65-74, 2019.

[68] A. R. Guntur and C. J. Rosen, "IGF-1 regulation of key signaling pathways in bone," BoneKEy Reports, vol. 2, p. 437, 2013.

[69] K. Nakao, M. Aoyama, H. Fukuoka et al., "IGF2 modulates the microenvironment for osteoclastogenesis," Biochemical 
and Biophysical Research Communications, vol. 378, no. 3, pp. 462-466, 2009.

[70] S. Avnet, M. Salerno, G. Quacquaruccio, D. Granchi, A. Giunti, and N. Baldini, "IGF2 derived from SH-SY5Y neuroblastoma cells induces the osteoclastogenesis of human monocytic precursors," Experimental Cell Research, vol. 317, no. 15, pp. 2147-2158, 2011.

[71] K. Li, S. Chen, P. Cai et al., "miRNA-483-5p is involved in the pathogenesis of osteoporosis by promoting osteoclast differentiation," Molecular and Cellular Probes, vol. 49, article 101479, 2020.

[72] V. Vijayan, M. Khandelwal, K. Manglani, S. Gupta, and A. Surolia, "Methionine down-regulates TLR4/MyD88/NF$\kappa \mathrm{B}$ signalling in osteoclast precursors to reduce bone loss during osteoporosis," British Journal of Pharmacology, vol. 171, no. 1, pp. 107-121, 2014.

[73] W. Wang, L. Yang, J. Wu et al., "The function of miR-218 and miR-618 in postmenopausal osteoporosis," European Review for Medical and Pharmacological Sciences, vol. 21, no. 24, pp. 5534-5541, 2017.

[74] M. A. Khadeer, S. N. Sahu, G. Bai, S. Abdulla, and A. Gupta, "Expression of the zinc transporter ZIP1 in osteoclasts," Bone, vol. 37, no. 3, pp. 296-304, 2005.

[75] Y. Wang, L. Li, B. T. Moore et al., "miR-133a in human circulating monocytes: a potential biomarker associated with postmenopausal osteoporosis," PLoS One, vol. 7, no. 4, article e34641, 2012.

[76] T. Kagiya and M. Taira, "Expression of microRNAs in the extracellular microvesicles of murine osteoclasts," Journal of Oral Tissue Engineering, vol. 10, pp. 142-150, 2013.

[77] T. Kagiya and S. Nakamura, "Expression profiling of microRNAs in RAW264.7 cells treated with a combination of tumor necrosis factor alpha and RANKL during osteoclast differentiation," Journal of Periodontal Research, vol. 48, no. 3, pp. 373385, 2013.

[78] P. Tang, Q. Xiong, W. Ge, and L. Zhang, "The role of microRNAs in osteoclasts and osteoporosis," RNA Biology, vol. 11, no. 11, pp. 1355-1363, 2014.

[79] M. Asagiri, K. Sato, T. Usami et al., "Autoamplification of NFATc1 expression determines its essential role in bone homeostasis," Journal of Experimental Medicine, vol. 202, no. 9, pp. 1261-1269, 2005.

[80] Y. Lee, H. J. Kim, C. K. Park et al., "MicroRNA-124 regulates osteoclast differentiation,” Bone, vol. 56, no. 2, pp. 383-389, 2013.

[81] K. Ohnuma, S. Kasagi, K. Uto et al., "MicroRNA-124 inhibits TNF- $\alpha$ - and IL-6-induced osteoclastogenesis," Rheumatology International, vol. 39, no. 4, pp. 689-695, 2019.

[82] Y. Cui, S. Fu, D. Sun, J. Xing, T. Hou, and X. Wu, "EPCderived exosomes promote osteoclastogenesis through IncRNA-MALAT1," Journal of Cellular and Molecular Medicine, vol. 23, no. 6, pp. 3843-3854, 2019.

[83] L. Ling, H. L. Hu, K. Y. Liu, Y. I. Ram, J. L. Gao, and Y. M. Cao, "Long noncoding RNA MIRG induces osteoclastogenesis and bone resorption in osteoporosis through negative regulation of miR-1897," European Review for Medical and Pharmacological Sciences, vol. 23, no. 23, pp. 10195-10203, 2019.

[84] L. Guo, K. Chen, J. Yuan et al., "Estrogen inhibits osteoclasts formation and bone resorption via microRNA-27a targeting PPAR $\gamma$ and APC," Journal of Cellular Physiology, vol. 234, no. 1, pp. 581-594, 2019.
[85] Y. Wan, L. W. Chong, and R. M. Evans, "PPAR- $\gamma$ regulates osteoclastogenesis in mice," Nature Medicine, vol. 13, no. 12, pp. 1496-1503, 2007.

[86] B. Qu, X. Xia, M. Yan et al., "miR-218 is involved in the negative regulation of osteoclastogenesis and bone resorption by partial suppression of p38MAPK-c-Fos-NFATc1 signaling: potential role for osteopenic diseases," Experimental Cell Research, vol. 338, no. 1, pp. 89-96, 2015.

[87] H. Takayanagi, S. Kim, and T. Taniguchi, "Signaling crosstalk between RANKL and interferons in osteoclast differentiation," Arthritis Research \& Therapy, vol. 4, article S227, Supplement 3, 2002.

[88] K. Inoue, Z. Deng, Y. Chen et al., "Bone protection by inhibition of microRNA-182," Nature Communications, vol. 9, no. 1, p. 4108, 2018.

[89] H. Zhao, J. Zhang, H. Shao et al., "Transforming growth factor beta1/Smad4 signaling affects osteoclast differentiation via regulation of miR-155 expression," Molecules and Cells, vol. 40, no. 3, p. 211, 2017.

[90] J. Zhang, H. Zhao, J. Chen et al., "Interferon- $\beta$-induced miR155 inhibits osteoclast differentiation by targeting SOCS1 and MITF," FEBS Letters, vol. 586, no. 19, pp. 3255-3262, 2012.

[91] T. Hayashi, T. Kaneda, Y. Toyama, M. Kumegawa, and Y. Hakeda, "Regulation of receptor activator of NF- $\kappa \mathrm{B}$ ligand-induced osteoclastogenesis by endogenous interferon- $\beta$ (INF- $\beta$ ) and suppressors of cytokine signaling (SOCS). The possible counteracting role of SOCSs- in IFNbeta-inhibited osteoclast formation," Journal of Biological Chemistry, vol. 277, no. 31, pp. 27880-27886, 2002.

[92] Z. Li, W. Zhang, and Y. Huang, "miRNA-133a is involved in the regulation of postmenopausal osteoporosis through promoting osteoclast differentiation," Acta Biochimica et Biophysica Sinica, vol. 50, no. 3, pp. 273-280, 2018.

[93] L. F. Coelho, G. M. de Freitas Almeida, F. J. D. Mennechet, A. Blangy, and G. Uze, "Interferon- $\alpha$ and $-\beta$ differentially regulate osteoclastogenesis: role of differential induction of chemokine CXCL11 expression," Proceedings of the National Academy of Sciences of the United States of America, vol. 102, no. 33, pp. 11917-11922, 2005.

[94] H. D. Jang, J. H. Shin, D. R. Park et al., "Inactivation of glycogen synthase kinase- $3 \beta$ is required for osteoclast differentiation," Journal of Biological Chemistry, vol. 286, no. 45, pp. 39043-39050, 2011.

[95] S. Sujitha and M. Rasool, "Berberine coated mannosylated liposomes curtail RANKL stimulated osteoclastogenesis through the modulation of GSK3 $\beta$ pathway via upregulating miR-23a," International Immunopharmacology, vol. 74, article 105703, 2019.

[96] J. Luo, Z. Yang, Y. Ma et al., "LGR4 is a receptor for RANKL and negatively regulates osteoclast differentiation and bone resorption," Nature Medicine, vol. 22, no. 5, pp. 539-546, 2016.

[97] F. Cong, N. Wu, X. Tian et al., "MicroRNA-34c promotes osteoclast differentiation through targeting LGR4," Gene, vol. 610, pp. 1-8, 2017.

[98] C. Liu, Z. Cao, Y. Bai et al., "LncRNA AK077216 promotes RANKL-induced osteoclastogenesis and bone resorption via NFATc1 by inhibition of NIP45," Journal of Cellular Physiology, vol. 234, no. 2, pp. 1606-1617, 2019.

[99] S. Shanmugarajan, C. J. Haycraft, S. V. Reddy, and W. L. Ries, "NIP45 negatively regulates RANK ligand induced osteoclast 
differentiation," Journal of Cellular Biochemistry, vol. 113, no. 4, pp. 1274-1281, 2012.

[100] C. P. Lee, Y. N. Huang, S. Nithiyanantham, C. M. Huang, and Y. C. Ko, "LncRNA-Jak3:Jak3 coexpressed pattern regulates monosodium urate crystal-induced osteoclast differentiation through Nfatc1/Ctsk expression," Environmental Toxicology, vol. 34, no. 2, pp. 179-187, 2019.

[101] Y. Wang, T. B. Luo, L. Liu, and Z. Q. Cui, "IncRNA LINC00311 promotes the proliferation and differentiation of osteoclasts in osteoporotic rats through the Notch signaling pathway by targeting DLL3," Cellular Physiology and Biochemistry, vol. 47, no. 6, pp. 2291-2306, 2018.

[102] C. Sekine, A. Koyanagi, N. Koyama, K. Hozumi, S. Chiba, and H. Yagita, "Differential regulation of osteoclastogenesis by Notch2/Delta-like 1 and Notch1/Jagged1 axes," Arthritis Research \& Therapy, vol. 14, no. 2, article R45, 2012.

[103] H. Fukushima, A. Nakao, F. Okamoto et al., "The association of Notch 2 and NF- $\kappa$ B accelerates RANKL-induced osteoclastogenesis," Molecular and Cellular Biology, vol. 28, no. 20, pp. 6402-6412, 2008.

[104] X. Zhang, Y. Zhao, Z. Zhao, X. Han, and Y. Chen, "Knockdown of DANCR reduces osteoclastogenesis and root resorption induced by compression force via Jagged1," Cell Cycle, vol. 18, no. 15, pp. 1759-1769, 2019.

[105] X. Tong, P. C. Gu, S. Z. Xu, and X. J. Lin, "Long non-coding RNA-DANCR in human circulating monocytes: a potential biomarker associated with postmenopausal osteoporosis," Bioscience, Biotechnology, and Biochemistry, vol. 79, no. 5, pp. 732-737, 2015.

[106] D. Bai, L. Ueno, and P. K. Vogt, "Akt-mediated regulation of $\mathrm{NF} \kappa \mathrm{B}$ and the essentialness of $\mathrm{NF} \kappa \mathrm{B}$ for the oncogenicity of PI3K and Akt," International Journal of Cancer, vol. 125, no. 12, pp. 2863-2870, 2009.

[107] J. B. Moon, J. H. Kim, K. Kim et al., “Akt induces osteoclast differentiation through regulating the GSK $3 \beta / \mathrm{NFATc1}$ signaling cascade," The Journal of Immunology, vol. 188, no. 1, pp. 163-169, 2011.

[108] Y. Sun, V. Kuek, Y. Liu et al., "miR-214 is an important regulator of the musculoskeletal metabolism and disease," Journal of Cellular Physiology, vol. 234, no. 1, pp. 231245, 2018.

[109] C. Zhao, W. Sun, P. Zhang et al., "miR-214 promotes osteoclastogenesis by targeting Pten/PI3k/Akt pathway," RNA Biology, vol. 12, no. 3, pp. 343-353, 2015.

[110] M. Li, R. Luo, W. Yang, Z. Zhou, and C. Li, "miR-363-3p is activated by MYB and regulates osteoporosis pathogenesis via PTEN/PI3K/AKT signaling pathway," In Vitro Cellular \& Developmental Biology. Animal, vol. 55, no. 5, pp. 376386, 2019.

[111] Z. Lou, Z. Peng, B. Wang, X. Li, X. Li, and X. Zhang, "miR$142-5 p$ promotes the osteoclast differentiation of bone marrow-derived macrophages via PTEN/PI3K/AKT/FoxO1 pathway," Journal of Bone and Mineral Metabolism, vol. 37, no. 5, pp. 815-824, 2019.

[112] Y. Han, C. Liu, M. Lei et al., "LncRNA TUG1 was upregulated in osteoporosis and regulates the proliferation and apoptosis of osteoclasts," Journal of Orthopaedic Surgery and Research, vol. 14, no. 1, p. 416, 2019.

[113] W. Li, H. Zhu, H. Xu, B. Zhang, and S. Huang, "CRNDE impacts the proliferation of osteoclast by estrogen deficiency in postmenopausal osteoporosis," European Review for Med- ical and Pharmacological Sciences, vol. 22, no. 18, pp. 58155821, 2018.

[114] S. M. Bartell, H. N. Kim, E. Ambrogini et al., "FoxO proteins restrain osteoclastogenesis and bone resorption by attenuating $\mathrm{H}_{2} \mathrm{O}_{2}$ accumulation," Nature Communications, vol. 5, no. 1, article 3773, 2014.

[115] C. H. Miller, S. M. Smith, M. Elguindy et al., "RBP-J-regulated miR-182 promotes TNF- $\alpha$-induced osteoclastogenesis," The Journal of Immunology, vol. 196, no. 12, pp. 49774986, 2016.

[116] K. Ke, M. A. Safder, O. J. Sul et al., "Hemeoxygenase-1 maintains bone mass via attenuating a redox imbalance in osteoclast," Molecular and Cellular Endocrinology, vol. 409, pp. 11-20, 2015.

[117] X. Ji, X. Chen, and X. Yu, "MicroRNAs in osteoclastogenesis and function: potential therapeutic targets for osteoporosis," International Journal of Molecular Sciences, vol. 17, no. 3, p. 349, 2016.

[118] K. Ke, O. J. Sul, M. Rajasekaran, and H. S. Choi, "MicroRNA183 increases osteoclastogenesis by repressing heme oxygenase-1," Bone, vol. 81, pp. 237-246, 2015.

[119] K. Reziwan, D. Sun, B. Zhang, and Z. Zhao, "MicroRNA-1225 activates Keap1-Nrf2-HO-1 signalling to inhibit TNF $\alpha$ induced osteoclastogenesis by mediating ROS generation," Cell Biochemistry and Function, vol. 37, no. 4, pp. 256-265, 2019.

[120] J. Y. Krzeszinski, W. Wei, H. D. Huynh et al., "miR-34a blocks osteoporosis and bone metastasis by inhibiting osteoclastogenesis and Tgif2," Nature, vol. 512, no. 7515, pp. 431435, 2014.

[121] H. Zhao, J. Zhang, H. Shao et al., "miRNA-340 inhibits osteoclast differentiation via repression of MITF," Bioscience Reports, vol. 37, no. 4, 2017.

[122] O. J. Sul, M. Rajasekaran, H. J. Park, J. H. Suh, and H. S. Choi, "MicroRNA-29b enhances osteoclast survival by targeting BCL-2-modifying factor after lipopolysaccharide stimulation," Oxidative Medicine and Cellular Longevity, vol. 2019, Article ID 6018180, 11 pages, 2019.

[123] K. Kim, J. H. Kim, J. Lee et al., "MafB negatively regulates RANKL-mediated osteoclast differentiation," Blood, vol. 109, no. 8, pp. 3253-3259, 2006.

[124] P. Cheng, C. Chen, H. B. He et al., "miR-148a regulates osteoclastogenesis by targeting V-maf musculoaponeurotic fibrosarcoma oncogene homolog B," Journal of Bone and Mineral Research, vol. 28, no. 5, pp. 1180-1190, 2013.

[125] K. Guo, D. Zhang, H. Wu, Q. Zhu, C. Yang, and J. Zhu, "miRNA-199a-5p positively regulated RANKL-induced osteoclast differentiation by target Mafb protein," Journal of Cellular Biochemistry, vol. 120, no. 5, pp. 7024-7031, 2018.

[126] K. Kim, J. Lee, J. H. Kim et al., "Protein inhibitor of activated STAT 3 modulates osteoclastogenesis by down-regulation of NFATc1 and osteoclast-associated receptor," The Journal of Immunology, vol. 178, no. 9, pp. 5588-5594, 2007.

[127] T. Liu, A. P. Qin, B. Liao et al., "A novel microRNA regulates osteoclast differentiation via targeting protein inhibitor of activated STAT3 (PIAS3)," Bone, vol. 67, pp. 156165, 2014.

[128] S. Yan, L. Miao, Y. Lu, and L. Wang, "MicroRNA-506 upregulation contributes to sirtuin 1 inhibition of osteoclastogenesis in bone marrow stromal cells induced by TNF- $\alpha$ treatment," Cell Biochemistry and Function, vol. 37, no. 8, pp. 598-607, 2019. 
[129] T. Franceschetti, C. B. Kessler, S. K. Lee, and A. M. Delany, "miR-29 promotes murine osteoclastogenesis by regulating osteoclast commitment and migration," Journal of Biological Chemistry, vol. 288, no. 46, pp. 33347-33360, 2013.

[130] I. D. Jansen, J. A. Vermeer, V. Bloemen, J. Stap, and V. Everts, "Osteoclast fusion and fission," Calcified Tissue International, vol. 90, no. 6, pp. 515-522, 2012.

[131] M. S. Lee, H. S. Kim, J. T. Yeon et al., "GM-CSF regulates fusion of mononuclear osteoclasts into bone-resorbing osteoclasts by activating the Ras/ERK pathway," The Journal of Immunology, vol. 183, no. 5, pp. 3390-3399, 2009.

[132] C. Dou, C. Zhang, F. Kang et al., "miR-7b directly targets DCSTAMP causing suppression of NFATc1 and c-Fos signaling during osteoclast fusion and differentiation," Biochimica et Biophysica Acta (BBA) - Gene Regulatory Mechanisms, vol. 1839, no. 11, pp. 1084-1096, 2014.

[133] Y. Yin, L. Tang, J. Chen, and X. Lu, "miR-30a attenuates osteoclastogenesis via targeting DC-STAMP-c-Fos-NFATc1 signaling," American Journal of Translational Research, vol. 9, article 5743, 2017.

[134] K. Kim, "MicroRNA-26a regulates RANKL-induced osteoclast formation," Molecules and Cells, vol. 43, pp. 591-670, 2015.

[135] T. Nishida, K. Emura, S. Kubota, K. M. Lyons, and M. Takigawa, "CCN family $2 /$ connective tissue growth factor (CCN2/CTGF) promotes osteoclastogenesis via induction of and interaction with dendritic cell-specific transmembrane protein (DC-STAMP)," Journal of Bone and Mineral Research, vol. 26, no. 2, pp. 351-363, 2011.

[136] C. Li, S. Wang, Z. Xing et al., "A ROR1-HER3-lncRNA signalling axis modulates the Hippo-YAP pathway to regulate bone metastasis," Nature Cell Biology, vol. 19, no. 2, pp. 106-119, 2017.

[137] S. Takigawa, A. Chen, Q. Wan et al., "Role of miR-222-3p in c-Src-mediated regulation of osteoclastogenesis," International Journal of Molecular Sciences, vol. 17, no. 2, p. 240, 2016.

[138] H. Touaitahuata, A. Blangy, and V. Vives, "Modulation of osteoclast differentiation and bone resorption by rho GTPases," Small GTPases, vol. 5, no. 1, article e28119, 2014.

[139] F. Mizoguchi, Y. Murakami, T. Saito, N. Miyasaka, and H. Kohsaka, "miR-31 controls osteoclast formation and bone resorption by targeting RhoA," Arthritis Research \& Therapy, vol. 15, no. 5, article R102, 2013.

[140] K. W. Lau and M. H. Sheng, "A novel miR17/protein tyrosine phosphatase-oc/EphA4 regulatory axis of osteoclast activity," Archives of Biochemistry and Biophysics, vol. 650, pp. 30-38, 2018.

[141] J. B. Fordham, K. Guilfoyle, A. R. Naqvi, and S. Nares, "miR$142-3 p$ is a RANKL-dependent inducer of cell death in osteoclasts," Scientific Reports, vol. 6, no. 1, 2016.

[142] S. Kakehi, K. Nakahama, and I. Morita, "Expression and possible role of PVR/CD155/Necl-5 in osteoclastogenesis," Molecular and Cellular Biochemistry, vol. 301, no. 1-2, pp. 209-217, 2007.

[143] S. L. Teitelbaum and F. P. Ross, "Genetic regulation of osteoclast development and function," Nature Reviews Genetics, vol. 4, no. 8, pp. 638-649, 2003.

[144] H. K. Vaananen, H. Zhao, M. Mulari, and J. M. Halleen, "The cell biology of osteoclast function," Journal of Cell Science, vol. 113, pp. 377-381, 2000.
[145] M. Matsumoto, M. Kogawa, S. Wada et al., "Essential role of p38 mitogen-activated protein kinase in cathepsin $\mathrm{K}$ gene expression during osteoclastogenesis through association of NFATc1 and PU.1," Journal of Biological Chemistry, vol. 279, no. 44, pp. 45969-45979, 2004.

[146] S. R. Wilson, C. Peters, P. Saftig, and D. Bromme, "Cathepsin $\mathrm{K}$ activity-dependent regulation of osteoclast actin ring formation and bone resorption," The Journal of Biological Chemistry, vol. 284, no. 4, pp. 2584-2592, 2009.

[147] M. Rossi, M. R. Pitari, N. Amodio et al., "miR-29b negatively regulates human osteoclastic cell differentiation and function: implications for the treatment of multiple myeloma-related bone disease," Journal of Cellular Physiology, vol. 228, no. 7, pp. 1506-1515, 2013.

[148] E. M'Baya-Moutoula, L. Louvet, V. Metzinger-Le Meuth, Z. A. Massy, and L. Metzinger, "High inorganic phosphate concentration inhibits osteoclastogenesis by modulating miR-223," Biochimica et Biophysica Acta (BBA) - Molecular Basis of Disease, vol. 1852, no. 10, pp. 2202-2212, 2015.

[149] H. Shibuya, T. Nakasa, N. Adachi et al., "Overexpression of microRNA-223 in rheumatoid arthritis synovium controls osteoclast differentiation," Modern Rheumatology, vol. 23, no. 4, pp. 674-685, 2014.

[150] F. Fazi, A. Rosa, A. Fatica et al., "A minicircuitry comprised of microRNA-223 and transcription factors NFI-A and C/EBP $\alpha$ regulates human granulopoiesis," Cell, vol. 123, no. 5, pp. 819-831, 2005.

[151] W. C. Horne, A. Sanjay, A. Bruzzaniti, and R. Baron, "The role(s) of Src kinase and Cbl proteins in the regulation of osteoclast differentiation and function," Immunological Reviews, vol. 208, no. 1, pp. 106-125, 2005.

[152] R. M. Scaife, S. A. Courtneidge, and W. Y. Langdon, "The multi-adaptor proto-oncoprotein $\mathrm{Cbl}$ is a key regulator of Rac and actin assembly," Journal of Cell Science, vol. 116, no. 3, pp. 463-473, 2002.

[153] S. Wang, C. Tang, Q. Zhang, and W. Chen, "Reduced miR-9 and miR-181a expression down-regulates Bim concentration and promote osteoclasts survival," International Journal of Clinical and Experimental Pathology, vol. 7, no. 5, article 2209, 2014.

[154] T. Matsubara, F. Ikeda, K. Hata et al., "Cbp recruitment of Csk into lipid rafts is critical to c-Src kinase activity and bone resorption in osteoclasts," Journal of Bone and Mineral Research, vol. 25, pp. 1068-1076, 2009.

[155] K. W. Lau, V. M. Stiffel, C. H. Rundle et al., "Conditional disruption of miR17 92 in osteoclasts led to activation of osteoclasts and loss of trabecular bone in part through suppression of the miR17-mediated downregulation of protein-tyrosine phosphatase-oc in mice," JBMR Plus, vol. 1, no. 2, pp. 73$85,2017$.

[156] T. Matsumoto, Y. Nagase, J. Hirose et al., "Regulation of bone resorption and sealing zone formation in osteoclasts occurs through protein kinase b-mediated microtubule stabilization," Journal of Bone and Mineral Research, vol. 28, no. 5, pp. 1191-1202, 2013.

[157] Y. Kaneshita, S. Goda, and T. Kawamoto, "The effect of matrix metalloproteinase- 9 on the differentiation into osteoclast cells on RAW264 cells," Orthodontic Waves, vol. 66, no. 4, pp. 122-128, 2007.

[158] J. Guo, X. Zeng, J. Miao et al., "miRNA-218 regulates osteoclast differentiation and inflammation response in 
periodontitis rats through Mmp9," Cellular Microbiology, vol. 21, no. 4, article e12979, 2019.

[159] E. Pivetta, M. Scapolan, M. Pecolo et al., "MMP-13 stimulates osteoclast differentiation and activation in tumour breast bone metastases," Breast Cancer Research, vol. 13, no. 5, article R105, 2011.

[160] Z. Wu, H. Yin, T. Liu et al., "miR-126-5p regulates osteoclast differentiation and bone resorption in giant cell tumor through inhibition of MMP-13," Biochemical and Biophysical Research Communications, vol. 443, no. 3, pp. 944-949, 2014.

[161] J.-M. Delaissé, T. L. Andersen, M. T. Engsig, K. Henriksen, T. Troen, and L. Blavier, "Matrix metalloproteinases (MMP) and cathepsin K contribute differently to osteoclastic activities," Microscopy Research and Technique, vol. 61, no. 6, pp. 504-513, 2003.

[162] X. Wu, M. A. McKenna, X. Feng, T. R. Nagy, and J. M. McDonald, "Osteoclast apoptosis: the role of Fas in vivo and in vitro," Endocrinology, vol. 144, no. 12, pp. 5545$5555,2003$.

[163] T. Sugatani and K. A. Hruska, "Down-regulation of miR-21 biogenesis by estrogen action contributes to osteoclastic apoptosis," Journal of Cellular Biochemistry, vol. 114, no. 6, pp. 1217-1222, 2013.

[164] H. M. Davis, R. Pacheco-Costa, E. G. Atkinson et al., "Disruption of the Cx43/miR21 pathway leads to osteocyte apoptosis and increased osteoclastogenesis with aging," Aging Cell, vol. 16, no. 3, pp. 551-563, 2017.

[165] Z. Zhou, J. Y. Han, C. X. Xi et al., "HMGB1 regulates RANKL-induced osteoclastogenesis in a manner dependent on RAGE," Journal of Bone and Mineral Research, vol. 23, no. 7, pp. 1084-1096, 2008.

[166] M. Shimada-Sugawara, E. Sakai, K. Okamoto et al., "Rab27A regulates transport of cell surface receptors modulating multinucleation and lysosome-related organelles in osteoclasts," Scientific Reports, vol. 5, no. 1, article 9620, 2015.

[167] L. Tang, Y. Yin, J. Liu, Z. Li, and X. Lu, "miR-124 attenuates osteoclastogenic differentiation of bone marrow monocytes via targeting Rab27a," Cellular Physiology and Biochemistry, vol. 43, no. 4, pp. 1663-1672, 2017.

[168] S. Salem, C. Gao, A. Li et al., "A novel role for interferon regulatory factor 1 (IRF1) in regulation of bone metabolism," Journal of Cellular and Molecular Medicine, vol. 18, no. 8, pp. 1588-1598, 2014.

[169] G. Sun, T. Guo, Y. Chen, B. Xu, J. H. Guo, and J. N. Zhao, "Significant pathways detection in osteoporosis based on the bibliometric network," European Review for Medical and Pharmacological Sciences, vol. 17, no. 1, pp. 1-7, 2013.

[170] S. Sang, Z. Zhang, S. Qin, C. Li, and Y. Dong, "MicroRNA-16$5 p$ inhibits osteoclastogenesis in giant cell tumor of bone," BioMed Research International, vol. 2017, Article ID 3173547, 6 pages, 2017.

[171] R. Chen, X. Zhang, X. Zhu, and C. Wang, "LncRNA Bmncr alleviates the progression of osteoporosis by inhibiting RANML-induced osteoclast differentiation," European Review for Medical and Pharmacological Sciences, vol. 23, no. 21, pp. 9199-9206, 2019.

[172] S. H. Lin, J. C. Ho, S. C. Li, J. F. Chen, C. C. Hsiao, and C. H. Lee, "miR-146a-5p expression in peripheral CD14 ${ }^{+}$monocytes from patients with psoriatic arthritis induces osteoclast activation, bone resorption, and correlates with clinical response," Journal of Clinical Medicine, vol. 8, no. 1, p. 110, 2019.

[173] Y. Sakaguchi, K. Nishikawa, S. Seno, H. Matsuda, H. Takayanagi, and M. Ishii, "Roles of enhancer RNAs in RANKL-induced osteoclast differentiation identified by genome-wide Cap-analysis of gene expression using CRISPR/Cas9," Scientific Reports, vol. 8, no. 1, p. 7504, 2018.

[174] K. Schaukowitch, J. Y. Joo, X. Liu, J. K. Watts, C. Martinez, and T. K. Kim, "Enhancer RNA facilitates NELF release from immediate early genes," Molecular Cell, vol. 56, no. 1, pp. 2942, 2014.

[175] S. He, S. Yang, Y. Zhang et al., "LncRNA ODIR1 inhibits osteogenic differentiation of hUC-MSCs through the FBXO25/H2BK120ub/H3K4me3/OSX axis," Cell Death of Disease, vol. 10, no. 12, p. 947, 2019.

[176] Q.-Y. Wu, X. Li, Z. N. Miao et al., "Long non-coding RNAs: a new regulatory code for osteoporosis," Frontiers in Endocrinology, vol. 9, p. 587, 2018.

[177] Z. Zou, W. Liu, L. Cao et al., "Advances in the occurrence and biotherapy of osteoporosis," Biochemical Society Transactions, 2020.

[178] D. P. Bartel, "MicroRNAs: genomics, biogenesis, mechanism, and function," Cell, vol. 116, no. 2, pp. 281-297, 2004.

[179] L. Cao, W. Liu, Y. Zhong et al., "Linc02349 promotes osteogenesis of human umbilical cord-derived stem cells by acting as a competing endogenous RNA for miR-25-3p and miR33b-5p," Cell Proliferation, vol. 53, no. 5, article e12814, 2020.

[180] N. Rucci, A. Zallone, and A. Teti, Isolation and Generation of Osteoclasts., Vol. 1914, Humana Press, 2019.

[181] K. J. Kim, J. T. Yeon, S. W. Choi et al., "Decursin inhibits osteoclastogenesis by downregulating NFATc1 and blocking fusion of pre-osteoclasts," Bone, vol. 81, pp. 208-216, 2015.

[182] A. S. Stephens, S. R. Stephens, and N. A. Morrison, "Internal control genes for quantitative RT-PCR expression analysis in mouse osteoblasts, osteoclasts and macrophages," BMC Research Notes, vol. 4, no. 1, p. 410, 2011.

[183] P. Mestdagh, P. van Vlierberghe, A. de Weer et al., "A novel and universal method for microRNA RT-qPCR data normalization," Genome Biology, vol. 10, no. 6, article R64, 2009.

[184] P. O. Brown and D. Botstein, "Exploring the new world of the genome with DNA microarrays," Nature Genetics, vol. 21, pp. 33-37, 1999.

[185] Y. Ma, Z. Shan, J. Ma et al., "Validation of downregulated microRNAs during osteoclast formation and osteoporosis progression," Molecular Medicine Reports, vol. 13, no. 3, pp. 2273-2280, 2016.

[186] S. Gallagher, S. E. Winston, S. A. Fuller, and J. G. R. Hurrell, "Immunoblotting and immunodetection," Current Protocols in Immunology, vol. 83, no. 1, pp. 8.10.11-18.10.28, 2008.

[187] P. M. Das, K. Ramachandran, J. VanWert, and R. Singal, "Chromatin immunoprecipitation assay," BioTechniques, vol. 37, no. 6, pp. 961-969, 2004.

[188] Z. Xu, X. Liu, H. Wang et al., "Lung adenocarcinoma cellderived exosomal miR-21 facilitates osteoclastogenesis," Gene, vol. 666, pp. 116-122, 2018.

[189] N. Chen, B. D. Sui, C. H. Hu et al., "MicroRNA-21 contributes to orthodontic tooth movement," Journal of Dental Research, vol. 95, no. 12, pp. 1425-1433, 2016.

[190] L. Gennari, S. Bianciardi, and D. Merlotti, "MicroRNAs in bone diseases," Osteoporosis International, vol. 28, no. 4, pp. 1191-1213, 2017. 
[191] T. Kagiya, "MicroRNAs: potential biomarkers and therapeutic targets for alveolar bone loss in periodontal disease," International Journal of Molecular Sciences, vol. 17, no. 8, p. 1317, 2016.

[192] X. Wang, B. Guo, Q. Li et al., "miR-214 targets ATF4 to inhibit bone formation," Nature Medicine, vol. 19, no. 1, pp. 93-100, 2013.

[193] Y. Yao, T. Jia, Y. Pan et al., "Using a novel microRNA delivery system to inhibit osteoclastogenesis," International Journal of Molecular Sciences, vol. 16, no. 12, pp. 8337-8350, 2015.

[194] M. Ammari, J. Presumey, C. Ponsolles et al., "Delivery of miR-146a to Ly6C $C^{\text {high }}$ monocytes inhibits pathogenic bone erosion in inflammatory arthritis," Theranostics, vol. 8, no. 21, pp. 5972-5985, 2018.

[195] A. Husain and M. A. Jeffries, "Epigenetics and bone remodeling," Current Osteoporosis Reports, vol. 15, no. 5, pp. 450458, 2017.

[196] C. Shi, J. Qi, P. Huang et al., "MicroRNA-17/20a inhibits glucocorticoid-induced osteoclast differentiation and function through targeting RANKL expression in osteoblast cells," Bone, vol. 68, pp. 67-75, 2014.

[197] X.-W. Wang, J.-J. Liu, Q.-N. Wu, S.-F. Wu, and D.-J. Hao, "The in vitro and in vivo effects of microRNA-133a on intervertebral disc destruction by targeting MMP9 in spinal tuberculosis," Life Sciences, vol. 188, pp. 198-205, 2017.

[198] C. H. Hu, B. D. Sui, F. Y. du et al., "miR-21 deficiency inhibits osteoclast function and prevents bone loss in mice," Scientific Reports, vol. 7, no. 1, article 43191, 2017.

[199] J. Liu, D. Li, L. Dang et al., "Osteoclastic miR-214 targets TRAF3 to contribute to osteolytic bone metastasis of breast cancer," Scientific Reports, vol. 7, no. 1, article 40487, 2017.

[200] S. Blüml, M. Bonelli, B. Niederreiter et al., "Essential role of microRNA-155 in the pathogenesis of autoimmune arthritis in mice," Arthritis \& Rheumatism, vol. 63, no. 5, pp. 12811288, 2011.

[201] Y. Nakamachi, K. Ohnuma, K. Uto, Y. Noguchi, J. Saegusa, and S. Kawano, "MicroRNA-124 inhibits the progression of adjuvant-induced arthritis in rats," Annals of the Rheumatic Diseases, vol. 75, no. 3, pp. 601-608, 2016.

[202] Y. T. Li, S. Y. Chen, C. R. Wang et al., "Brief report: amelioration of collagen-induced arthritis in mice by lentivirusmediated silencing of microRNA-223," Arthritis \& Rheumatism, vol. 64, no. 10, pp. 3240-3245, 2012. 